\title{
Modeling study of mesospheric planetary waves: genesis and characteristics
}

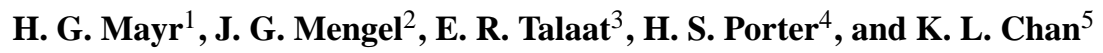 \\ ${ }^{1}$ Goddard Space Flight Center, Greenbelt, MD, 20771, USA \\ ${ }^{2}$ Science Systems \& Applications, Inc., Lanham, MD, USA \\ ${ }^{3}$ Applied Physic Laboratory, Johns Hopkins University, Laurel, MD, USA \\ ${ }^{4}$ Furman University, Greenville, SC, USA \\ ${ }^{5}$ Hong Kong University of Science and Technology, Hong Kong, China
}

Received: 13 November 2003 - Revised: 1 March 2004 - Accepted: 4 March 2004 - Published: 14 June 2004

\begin{abstract}
The Numerical Spectral Model (NSM) extends from the ground into the thermosphere and incorporates Hines' Doppler Spread Parameterization for smallscale gravity waves (GWs). In the present version of the model we account for a tropospheric heat source in the zonal mean $(\mathrm{m}=0)$, which reproduces qualitatively the observed zonal jets near the tropopause and the accompanying reversal in the latitudinal temperature variations. In the study presented here, we discuss the planetary waves (PWs) that are solely generated internally, i.e. without the explicit excitation sources related to tropospheric convection or topography. Our analysis shows that PWs are not produced when the zonally averaged heat source into the atmosphere is artificially suppressed, and that the PWs are generally weaker when the tropospheric source is not applied. Instabilities associated with the zonal mean temperature, pressure and wind fields, which still need to be explored, are exciting PWs that have amplitudes in the mesosphere comparable to those observed. Three classes of PWs are generated in the NSM. (1) Rossby type PWs, which slowly propagate westward relative to the mean zonal flow, are carried by the winds so that they appear (from the ground) to propagate, respectively, eastward and westward in the winter and summer hemispheres below $80 \mathrm{~km}$. Depending on the zonal wave number and magnitudes of the zonal winds, and under the influence of the equatorial oscillations, these PWs typically have periods between 2 and 20 days. Their horizontal wind amplitudes can exceed $40 \mathrm{~m} / \mathrm{s}$ in the lower mesosphere. (2) Rossby-gravity waves, which propagate westward at low latitudes and have periods around 2 days for zonal wave numbers $m=2$ to 4 . (3) Eastward propagating equatorial Kelvin waves, which are generated in the upper mesosphere with periods between 1 and 3 days depending on $\mathrm{m}$. A survey of the PWs reveals that the largest wind amplitudes tend to occur below $80 \mathrm{~km}$ in the winter hemisphere; but above that altitude the amplitudes
\end{abstract}

are larger in the summer hemisphere where the winds can approach $50 \mathrm{~m} / \mathrm{s}$. This pattern in the seasonal variations also appears in the baroclinity of the zonal mean $(m=0)$. The nonmigrating tides in the mesosphere are significantly larger for the model with the tropospheric heat source, in which PWs are apparently generated by the instabilities that arise around the tropopause.

Key words. Meteorology and atmospheric dynamics (general circulation; middle atmosphere dynamics, waves and tides)

\section{Introduction}

As is true for the troposphere and stratosphere, planetary waves (PW) feature prominently in the observed phenomenology of the mesosphere. At altitudes between 80 and $100 \mathrm{~km}$, planetary wave oscillations have been observed with spacecraft measurements (e.g. Hays et al., 1993; Shepherd et al., 1993; Wu et al., 1993, 1994; Smith, 1996; 1997; Fritts et al., 1999; Wang et al., 2000, Talaat and Lieberman, 1999, Talaat et al., 2001) and with ground-based observations (e.g. Muller and Nelson, 1978; Fraser et al., 1993; Craig and Elford, 1981; Burks and Leovy, 1986; Tsuda et al., 1988; Phillips, 1989; Poole, 1990; Clark et al., 1994; Fritts and Isler, 1994; Meek et al., 1996; Deng et al., 1997; Williams et al., 1999; Harris, 1994; Harris and Vincent, 1993).

The theoretical properties of PWs in general are well understood and have been extensively discussed in the literature (e.g. Holton, 1979; Volland, 1988; Forbes, 1995). Our understanding, however, is less developed when we ask how, where, and under what dynamical conditions the waves are generated. 
In the troposphere and near the ground, topographic forcing and tropical convection can generate PWs, such as the equatorially trapped Kelvin waves and Rossby-gravity waves that are involved in driving the Quasi-biennial Oscillation (QBO) and Semiannual Oscillation (SAO) in the stratosphere (Lindzen and Holton, 1968). The PWs originating in the troposphere, however, cannot propagate through the stratosphere without being partially absorbed. A significant portion of the waves observed in the mesosphere thus may be excited in-situ, and the dynamical conditions there are well suited for that. Due to gravity wave breaking (Lindzen, 1981), the zonal circulation in the upper mesosphere reverses, and associated with that the latitudinal temperature and pressure gradients have opposite signs. This contributes to making the region baroclinically unstable, which can provide the energy to excite PWs as Plumb (1983) and Pfister (1985) had proposed.

The dynamical conditions around the tropopause are to some extent similar to those in the upper mesosphere. $\mathrm{Cu}$ mulus heating at low latitudes and the resulting temperature variations generate in geostrophic balance the observed zonal jets near the tropopause. The associated meridional circulation, with upwelling at the equator, produces there dynamical cooling and redistributes the energy. This causes the temperature above the zonal jets to decrease around the equator and increase at higher latitudes, which should contribute to instabilities that launch PWs.

Another important aspect of this tropospheric heat source is directly associated with the meridional circulation it generates. As Dunkerton $(1985,1997)$ pointed out, the related upward vertical winds can be comparable in magnitude to the downward propagation velocity of the QBO. This affects the period of the QBO, and the dynamical forcing required to generate the oscillation then needs to be larger (Gray and Pile, 1989; Dunkerton, 1985; Kinnersley and Pawson, 1996).

Motivated by the dynamical conditions just outlined, we extended the NSM to incorporate a tropospheric heat source in the zonal mean $(\mathrm{m}=0)$ to reproduce qualitatively the observed zonal jets and associated temperature variations near the tropopause.

After a description of the NSM, we present numerical results for the zonal mean $(\mathrm{m}=0)$ that characterize (a) the global-scale seasonal variations of the zonal circulation and temperature variations, and (b) the wave driven equatorial oscillations (QBO and SAO). In the main body of the paper, we then discuss under different dynamical conditions the planetary waves that are generated in the model. We apply spectral analysis to identify the different planetary wave modes and conclude by summarizing the results.

\section{Numerical spectral model (NSM)}

The design of the Numerical Spectral Model (NSM) was introduced by Chan et al. (1994), and we applied 2-D and 3-D versions of this model to study some aspects of the middle atmosphere dynamics (e.g. Mengel et al., 1995; Mayr et al.,
1997, 2001a, b). The model has been discussed in the literature and is briefly reviewed here for completeness.

The NSM is nonlinear and time dependent. Formulated with spherical harmonics, the NSM delineates the dynamical components in terms of zonal wave numbers: $m=0$ for the zonal mean that includes the Semiannual Oscillation (SAO) and Quasi-biennial Oscillation (QBO), and $m=1$ to 4 for the tides and planetary waves. The wave number truncation of the model can affect the planetary waves due to nonlinear interactions involving the higher order unresolved dynamical components. Since the wave spectrum tends to fall off with increasing wave number, however, it seems reasonable to assume that the effect is relatively small.

The Navier Stokes equations are solved to describe the variations around the global mean of temperature and density, covering the atmosphere from the ground up to $400 \mathrm{~km}$ (240 km in the present application to speed up computation). By marching in time, the equations are solved for the spherical harmonics, and their synthesis provides the solution. The nonlinear terms are evaluated in physical space. The NSM is run with a vertical step size of about $0.5 \mathrm{~km}$ (below $120 \mathrm{~km}$ ) and a time step of about 5 minutes.

The following external sources drive the NSM:

1. For the zonal mean $(m=0)$, the heat source is due to UV radiation in the mesosphere and stratosphere taken from Strobel (1978) and due to EUV radiation in the thermosphere.

2. For the solar driven migrating tides, the heating rates in the middle atmosphere and troposphere are taken from Forbes and Garrett (1978).

3. Our approach in modeling the tropopause jets and associated meridional circulation, with rising motions at the equator that extend into the lower stratosphere, is partially based on the analysis and understanding developed in a series of papers (Held and Hou, 1980; Lindzen and Hou, 1988; Plumb and Hou, 1992). The heat source is taken to be symmetric around the equator and independent of season. The latitude dependence of the source is modeled with the Legendre polynomial $\mathrm{P}_{2}$ to produce an effective forcing that changes sign near $35^{\circ}$ latitude. For the purpose of this study, we chose the heating rates in the troposphere such that the model qualitatively reproduces the observed features of the zonal circulation and temperature variations.

The radiative loss in the model is described in terms of Newtonian cooling, which was originally taken from Wehrbein and Leovy (1982). More recently, we have applied in our model the cooling parameterization of Zhu (1989).

The NSM incorporates the Doppler Spread Parameterization (DSP) for small-scale gravity waves (GW) formulated by Hines $(1997 a, b)$. The theory for this parameterization was developed in a series of earlier papers (Hines, 1991a, b), and it has recently been further solidified (Hines, 2001, 2002). The DSP deals with a spectrum of waves that interact 

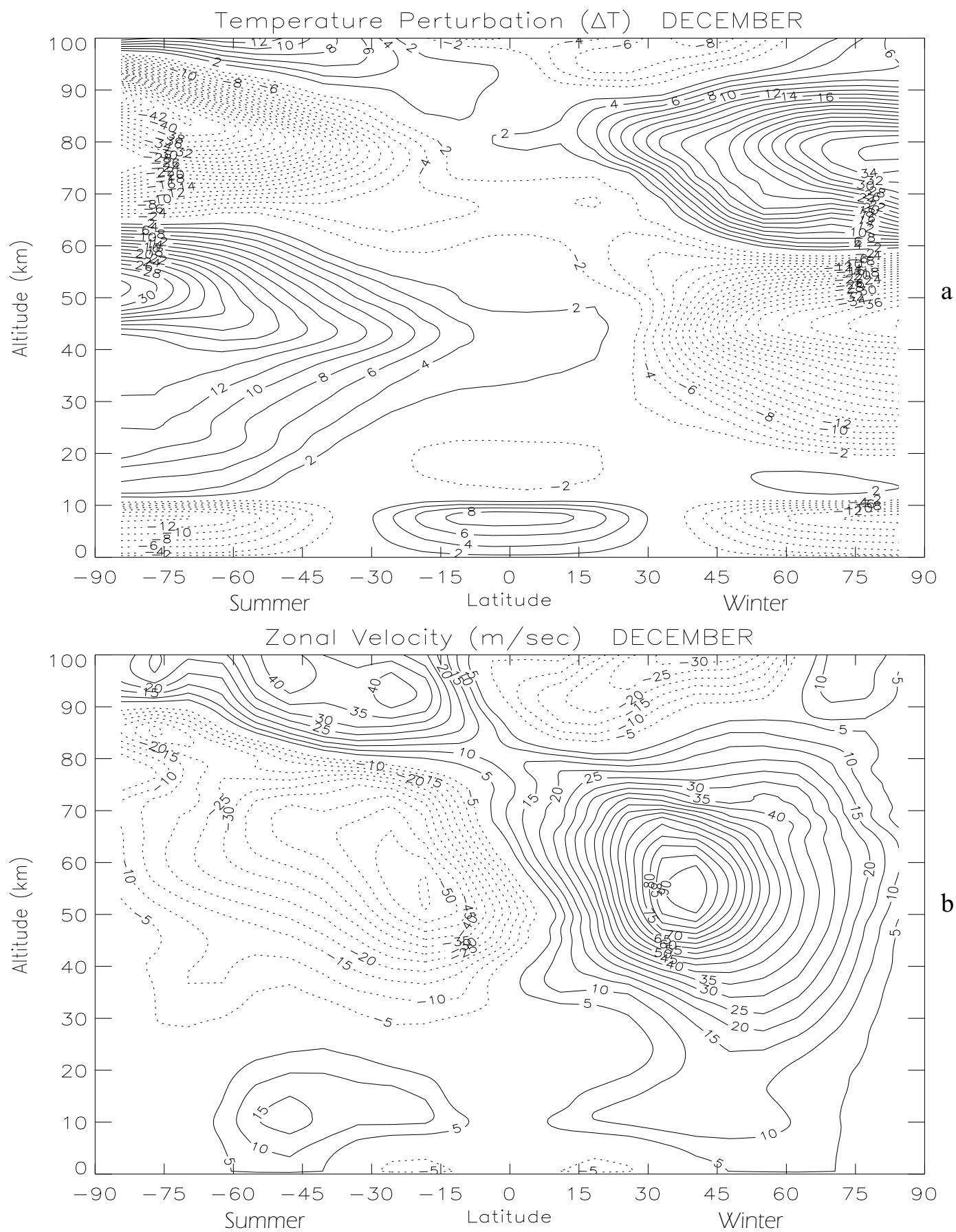

Fig. 1. Zonal-mean $(m=0)$ temperature perturbations $(\mathbf{a})$ and zonal winds $(\mathbf{b})$, which are computed with the tropospheric heat source. The contour plots are derived by averaging December solstice conditions for five consecutive years. Above the tropopause and $65 \mathrm{~km}$, the reversals in the latitudinal temperature gradients significantly affect the pressure and density gradients, and this contributes to producing the instabilities that generate the PWs in the model.

with each other to produce Doppler spreading. This affects the interaction of the waves with the background flow, which is important for the dynamics of the middle atmosphere in general and for generating the QBO in particular. The DSP has also been applied successfully in a number of other models (e.g. Akmaev, 2001; Manzini et al., 1997).
In the NSM, the GW source at the initial height (for the present model taken to be $7.5 \mathrm{~km}$ ) is assumed to be isotropic and independent of latitude and season. The DSP assures conservation of GW momentum (and energy), and this requires at each altitude, latitude and longitude that a system of nonlinear equations is solved, involving GW parameters, background winds, and buoyancy frequency. Applying 


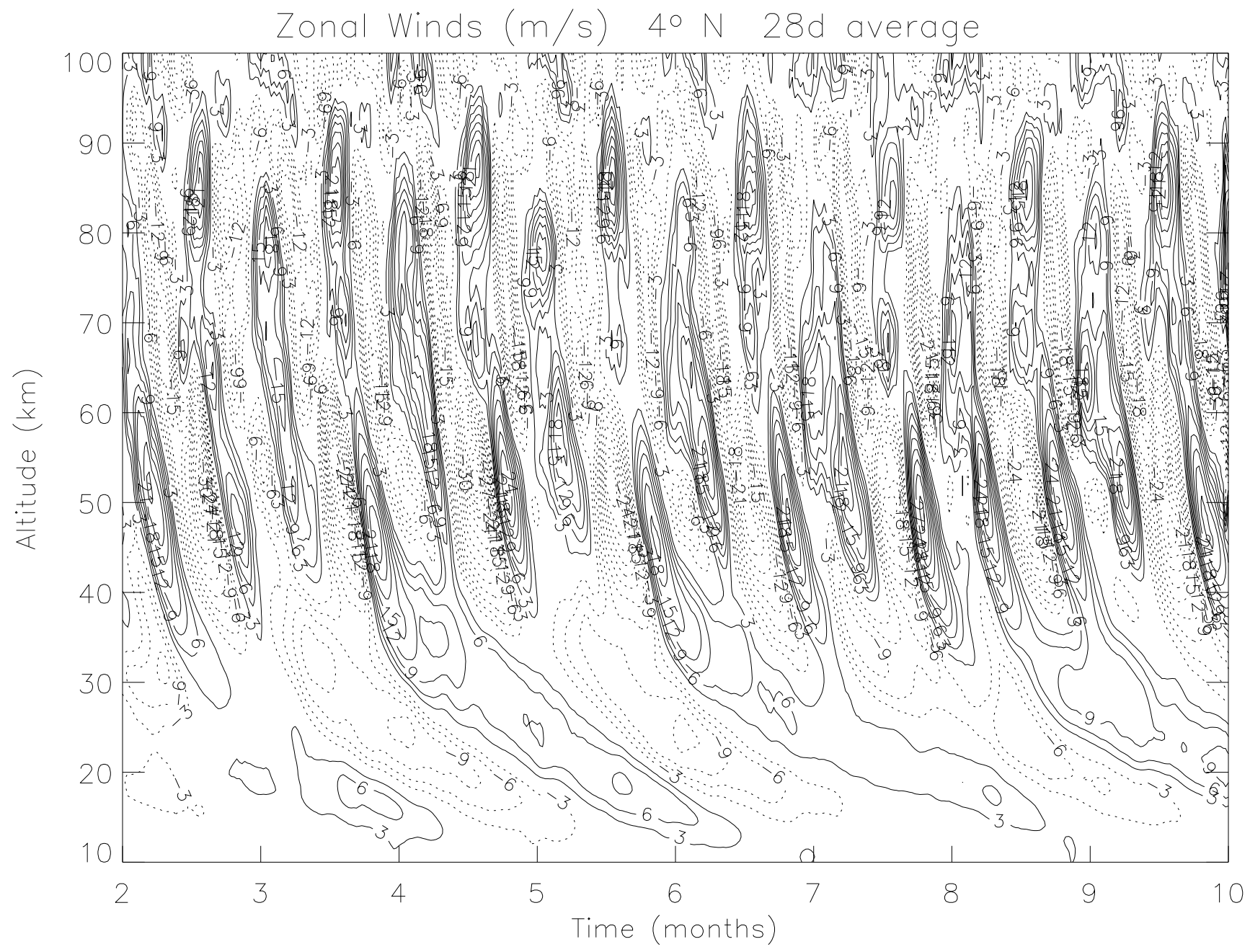

Fig. 2. Equatorial oscillations generated by GWs. The QBO period is close to 28 months, near the middle of observed values, but its amplitude is relatively small. (Numerical experiments show that more realistic QBO amplitudes can be produced with a latitude dependent GW source that is enhanced at the equator.)

Newtonian iteration, convergence is assured by adjusting the time integration step. With an adjustable parameterization factor, the DSP also provides height dependent eddy diffusion rates (isotropic), which are incorporated into the NSM under the assumption that the variations with latitude and season can be ignored. The heating rates associated with the dissipation of GWs are not accounted for.

\section{Zonal mean $(m=0)$}

In Fig. 1 we present for December solstice contour plots of (a) the temperature perturbations (around the global mean) and (b) the zonal winds, both computed with the tropospheric heat source. In the troposphere up to $10 \mathrm{~km}$, the applied heat source causes the temperature to increase at low latitudes around the equator and to decrease at mid to high latitudes. Above the tropopause, in the lower stratosphere, the temperature decreases around the equator and increases towards higher latitudes, which is in qualitative agreement with observations. The pressure variations associated with these temperature variations produce in geostrophic balance zonal jets near the tropopause, which have velocities close to $15 \mathrm{~m} / \mathrm{s}$ that are somewhat smaller than those observed.

In the stratosphere and lower mesosphere, the computed temperatures decrease in winter and increase in summer due to the seasonal variations of solar heating. Higher up in the mesosphere, however, the latitudinal temperature gradient reverses as a result of gravity wave interaction with the zonal circulation (Lindzen, 1981), which produces the anomalous low temperatures in the summer hemisphere that are observed. Commensurate with the temperature variations, the zonal winds in the stratosphere are eastward in winter and westward in summer below $80 \mathrm{~km}$, and they reverse in the upper mesosphere.

As pointed out earlier, the configurations of the computed temperature and wind fields in the mesosphere (Figs. 1a and $1 \mathrm{~b}$, respectively) imply that the latitudinal gradients of temperature and pressure have opposite signs. This in turn increases the difference between the relative gradients of 
pressure and density, which is conducive to generate the baroclinic instability that has been invoked to generate planetary waves (Plumb, 1983). With the temperature reversal near the tropopause, the dynamical conditions there are similar, and this should contribute to the generation of the planetary waves later discussed.

The other aspect of the tropospheric heat source relates to the upwelling at low latitudes, which is associated with the meridional circulation that in turn causes, through adiabatic overshooting, the above discussed temperature reversal above the tropopause. Driven by differential heating, the meridional winds extend to altitudes above the source such that dynamical cooling dominates around the equator to reverse the latitudinal temperature variations. At low latitudes, in the present model, the vertical winds associated with this meridional circulation are on average about $0.15 \mathrm{~mm} / \mathrm{s}$ at $30 \mathrm{~km}$, which are smaller than the values inferred from water vapor anomalies (Mote et al., 1996). Vertical winds of this magnitude affect significantly the QBO, which is reproduced in Fig. 2. The period of the oscillation is about 28 months, close to the middle of the observed range. Without the tropospheric source (and vanishing vertical winds below $20 \mathrm{~km}$ ), the zonal wind oscillations (not shown) have periods that are much shorter, only about 18 months. The QBO amplitude in the present model is relatively small, but this is not a serious problem. Numerical experiments show that we could generate larger QBO amplitudes by adopting a GW source that is enhanced at equatorial latitudes, owing to stronger tropospheric convection.

For the purpose of this paper, no attempt was made to tune the model to reproduce the observations. The primary purpose of this study is to describe the mesospheric PWs that are generated in the NSM under different dynamical conditions and in particular under the influence of tropospheric heating. The waves are solely generated by instabilities, which still need to be explored.

\section{Planetary wave genesis}

Anticipating the numerical results to be discussed, we show with Fig. 3 a schematic that illustrates the dynamical features and processes involved in generating the PWs in the NSM. For the modeling study presented here, we emphasize again that no explicit PW source of any kind is prescribed, neither thermally nor through the momentum forcing. The model is driven by solar heating, which is the source for (a) the mean zonal circulation and (b) the westward migrating diurnal and semidiurnal tides. In addition, a steady source of parameterized small-scale gravity waves (GW) is imposed, which for simplicity is taken to be independent of latitude and season. As outlined in Fig. 3 and earlier discussed, the GWs produce temperature and wind reversals in the upper mesosphere (1). They also affect significantly the tides (2) and planetary waves (3). It was demonstrated for the NSM (Mayr et al., 2003) that nonlinear coupling between migrating tides and PWs can produce nonmigrating tides in the upper meso-

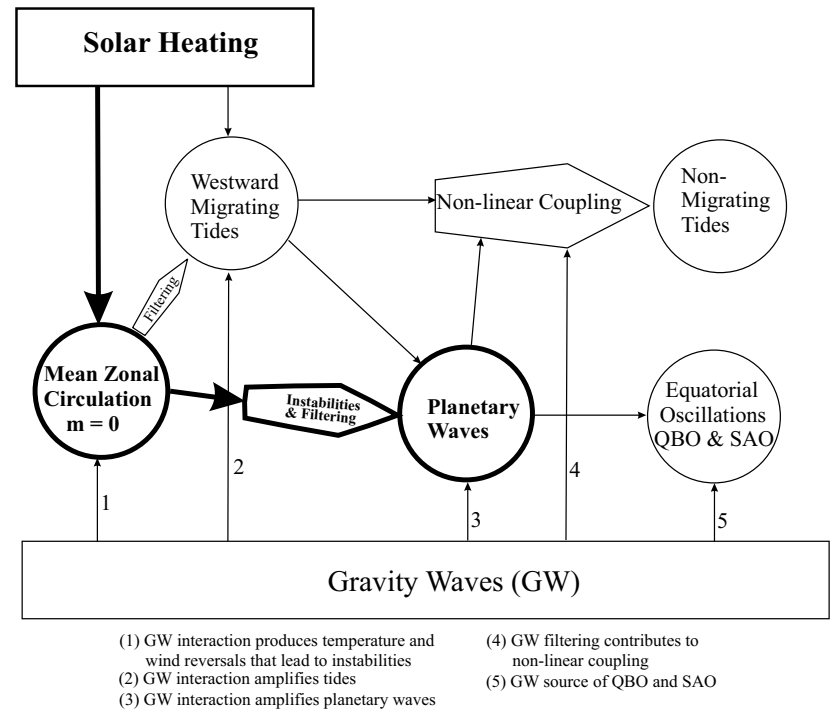

Fig. 3. Schematic illustrating the dynamical features and processes involved in generating the PWs. In the mean zonal circulation $(\mathrm{m}=0)$, which includes the jets near the tropopause, the PWs are generated by instabilities, and they are modified by filtering. The nonmigrating tides in the NSM are produced by nonlinear coupling between migrating tides and PWs. As enumerated in the figure, GW interactions cause in the mesosphere reversals in the zonal winds and temperature variations. The GWs amplify the PWs (and tides), and they generate the QBO.

sphere with amplitudes comparable to those observed. By artificially turning off the solar heating for the mean zonal circulation, the PWs were suppressed in the model and so were the nonmigrating tides. As Fig. 3 illustrates, the GWs contribute in several important ways to the nonmigrating tides by influencing significantly their building blocks, i.e. the tides and PWs. The GWs completely change the mean zonal circulation and temperature variations above $60 \mathrm{~km}$ (Lindzen, 1981), which in turn affects the instabilities that generate the PWs. The GWs also contribute to the nonlinear coupling (4) between the tides and PWs. And the GWs generate the QBO and amplify the SAO (5).

To elucidate some of the sources of PWs and the regions where they originate, we present the following numerical results obtained under three different conditions. Generated by the full source that drives the zonal-mean $(\mathrm{m}=0)$ circulation, including the above discussed tropospheric heating, we show for zonal wave numbers $m=1$ to 4 the zonal winds in Fig. $4 \mathrm{a}$ and the temperature perturbations in Fig. $4 \mathrm{~b}$, both computed at $48^{\circ}$ latitude and $90 \mathrm{~km}$ altitude. Evidently, the PW oscillations are highly variable but reveal persistent seasonal variations, as seen, for example, in the short period waves during summer months for $\mathrm{m}=3$ and 4 , and in the long period waves around equinox that appear in all the wave numbers. For comparison, we present in Fig. 5a the PWs for the zonal winds computed from a model without the tropospheric heat source. In this case, the short period PWs for $\mathrm{m}=3$ and 4 in summer are comparable to those in Fig. 4a, but otherwise the PW amplitudes are significantly smaller. 

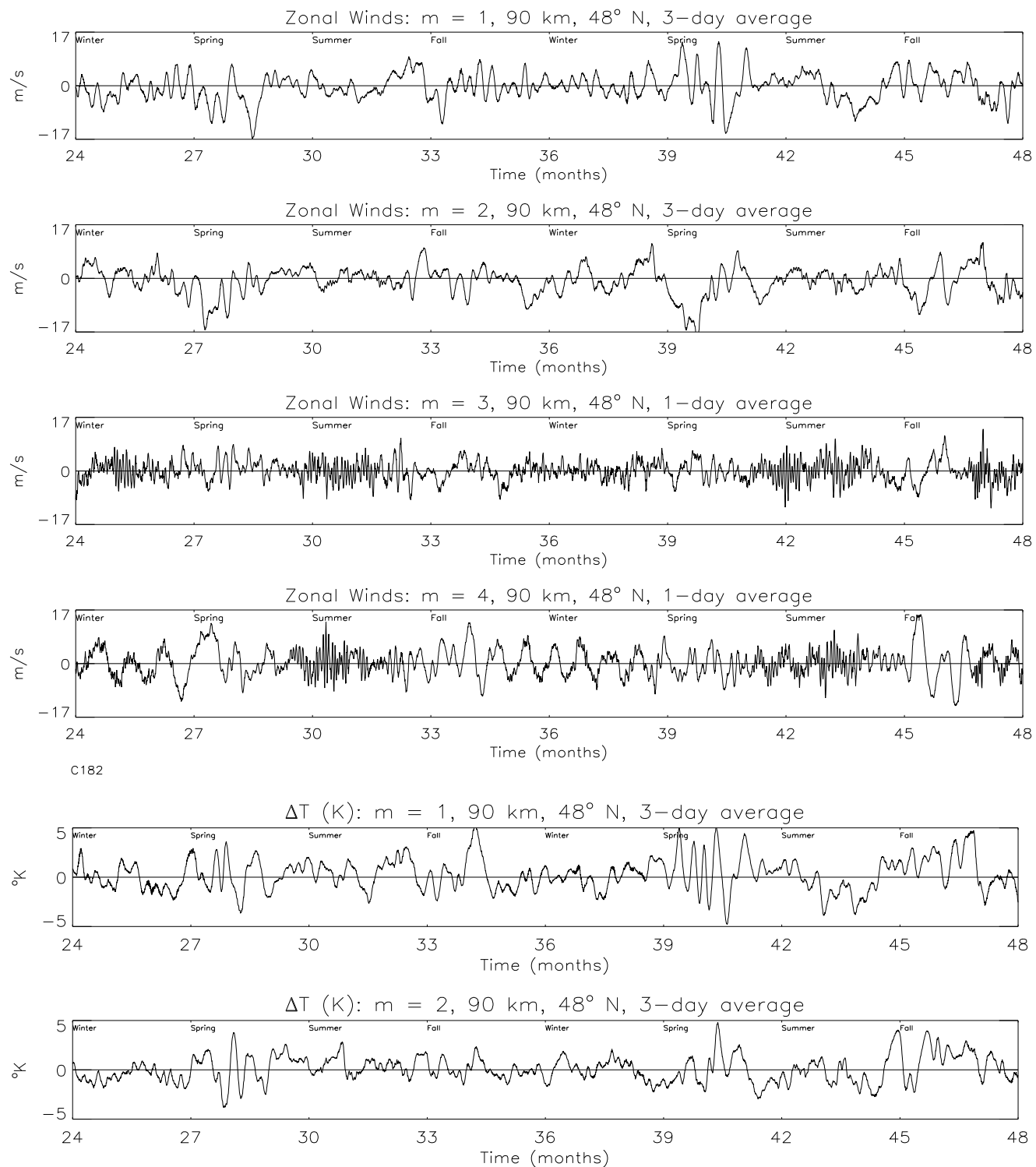

$\mathrm{b}$
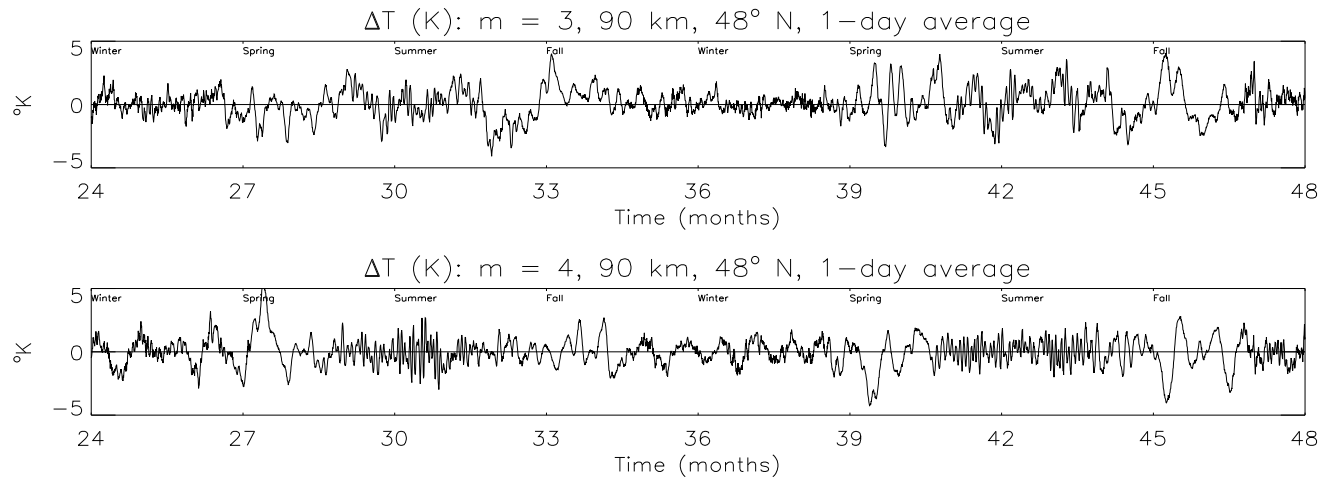

Fig. 4. Zonal wind (a) and temperature perturbations (b) of PWs for $\mathrm{m}=1$ to 4 at $90 \mathrm{~km}$ altitude and $48^{\circ}$ latitude, computed at $0^{\circ}$ longitude over a time span of 2 years with the standard model that includes the tropospheric heat source. Note the persistent seasonal variations, e.g. the short period (2- to 3-day) waves during summer months for $\mathrm{m}=3$ and 4 , and the long period waves during spring and fall in particular for $\mathrm{m}=1$ and 2 . 
Without Tropospheric Zonal Mean ( $\mathrm{m}=0$ ) Heat Source
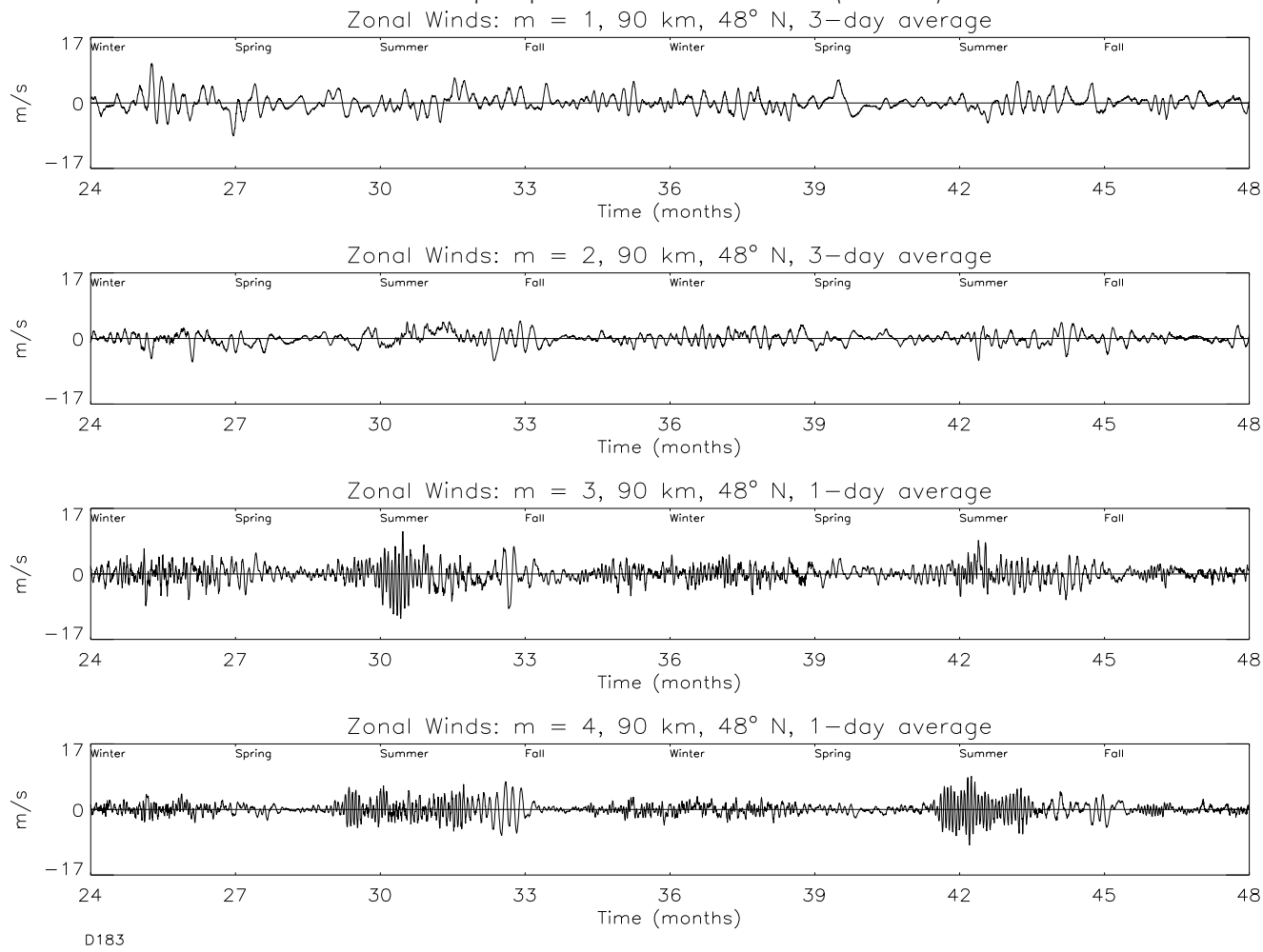

Without Atmospheric Zonal Mean ( $m=0$ ) Heat Source
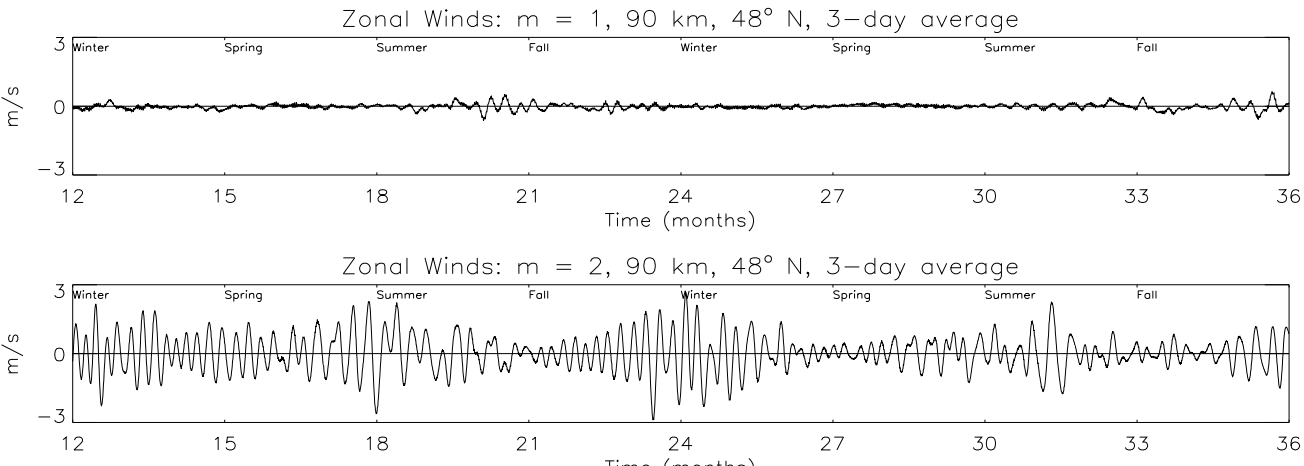

$\mathrm{b}$
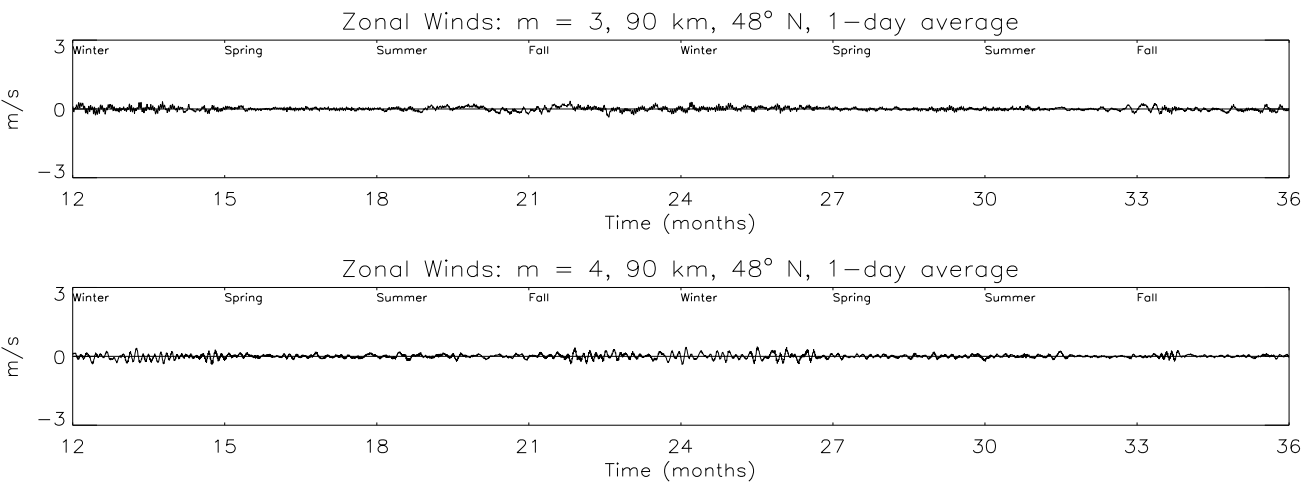

Fig. 5. (a) Analogous to Fig. 4a but computed without tropospheric heating. Compared to the standard model with the tropospheric source (Fig. 4a), the short period waves for $\mathrm{m}=3$ and 4 are similar in magnitude, but the amplitudes of the long period waves are significantly smaller in particular for $\mathrm{m}=1$ and 2. This affects significantly the nonmigrating tides as shown in Fig. 6. (b) Analogous to Fig. 4a but computed without a heat source for $\mathrm{m}=0$ throughout the atmosphere. Although PWs are generated, e.g. for $\mathrm{m}=2$ in particular, their amplitudes are small by comparison (note the differences in scales). 
Finally, we show in Fig. 5b the PWs computed without the $m=0$ source throughout the atmosphere, and the amplitudes then are small (note the differences in the scales). This indicates that the PWs are apparently generated by the instabilities, which still need to be identified, that arise in the mean zonal circulation and associated temperature and pressure variations as illustrated in Fig. 3. For reasons not understood, the wave amplitudes in $\mathrm{m}=2$ are curiously much larger than those of the other wave numbers in Fig. 5b.

It is appropriate here to show some results for the nonmigrating tides, which are generated in the NSM by nonlinear coupling involving PWs (illustrated in Fig. 3) as Teitelbaum and Vial (1991) originally proposed. Two solutions are presented in Figs. $6 \mathrm{a}$ and $6 \mathrm{~b}$ for the $\mathrm{m}=0$ nonmigrating diurnal tide and in Figs. $6 \mathrm{c}$ and $6 \mathrm{~d}$ for the $\mathrm{m}=1$ semidiurnal tide, computed in each case with and without the influence from the tropospheric $m=0$ heat source. (One can readily verify that PWs with $\mathrm{m}=1$ are involved to generate these tides.) Without the tropospheric source $(b, d)$, the computed amplitudes are significant, and they reveal systematic seasonal variations. But with the source (a, c), the amplitudes are larger, commensurate with the differences in the PWs shown in Figs. 4a and $5 \mathrm{a}$.

Prominent PWs are generated in the model for $\mathrm{m}=3$ (and 4 , not presented) at low latitudes, which have periods between 2 and 4 days, and we show the meridional winds and temperature variations in Figs. 7a and 7b, respectively, for a number of altitudes from 20 to $90 \mathrm{~km}$. These are Rossby-gravity waves, and Plumb (1983) proposed that they are generated preferentially during solstice by the instabilities that develop in the latitudinal variations (across the equator) of the zonal mean $(\mathrm{m}=0)$ state variables. The 2-day waves dominate in the winds and temperature, except at $20 \mathrm{~km}$ where the long period waves prevail that have relatively small amplitudes at this altitude.

Close examination of the PWs for $\mathrm{m}=3$ (and 4, not presented) reveals that the seasonal variations drastically change when we go from the upper stratosphere into the mesosphere. This is shown with Figs. 8a and 8b, where we present, respectively, at 60 and $90 \mathrm{~km}$, contour plots of the meridional winds for the $m=3$ PWs with periods between 1 and 5 days. At $60 \mathrm{~km}$, the largest PWs are generated preferentially in the winter hemisphere, and the waves extend across the equator into the summer hemisphere. At $90 \mathrm{~km}$, the PWs also extend across the equator, but the waves at that altitude are more prevalent in the summer hemisphere.

As a measure of baroclinity, we computed the differences between the relative latitudinal pressure and density gradients in the zonal mean $(\mathrm{m}=0)$. Given the pressure and density perturbations, $\Delta \mathrm{P}$ and $\Delta \mathrm{N}$, that are derived in the model as perturbations of the global mean, $\mathrm{P}_{o}$ and $\mathrm{N}_{o}$, we evaluated $\gamma=\partial\left(\Delta \mathrm{P} / \mathrm{P}_{o}\right) / \partial \theta-\partial\left(\Delta \mathrm{N} / \mathrm{N}_{o}\right) / \partial \theta$, and the parameter is presented with contour plots in Fig. 9. This shows that $\gamma$ for $\mathrm{m}=0$ tends to be largest in winter at $50 \mathrm{~km}$ and $70 \mathrm{~km}$. But at $90 \mathrm{~km}$, above a transition region around $80 \mathrm{~km}$, the normalized gradients are larger during summer months. The pattern in the seasonal variations, including the changes with alti- tude, thus resembles the pattern in the PWs evident in Fig. 8 - which suggests that the baroclinic instability is involved in generating the waves.

\section{Planetary wave modes}

In the limited space of a paper it is not possible to provide a comprehensive description of the PWs that are generated. We therefore restrict ourselves to present a few samples that appear to be representative of the season right after solstice.

To reveal the properties of the PWs, the dominant wave periods are determined from Fourier analysis covering the time span of January and February of the third model year (24 to 26 model months). Running windows are applied that are multiples (factor of 3 in the present case) of a given period, and the largest amplitudes are recorded for the eastward and westward propagating waves associated with different zonal wave numbers. Starting with the lowest period (one day in this case), a 3-day running window is applied to derive the wave amplitude from the third harmonic. This fixed window is advanced by one day to cover the time span that is analyzed. Subsequently, the running windows are then increased each time by one day to compute the amplitudes for the periods of $4 / 3,5 / 3$ and so on. For each of these increasing running windows, the third harmonic again determines the corresponding wave amplitudes.

In Figs. 10a and 10b, we present for $m=3$ at $60 \mathrm{~km}$, as functions of latitude, the amplitudes of the zonal and meridional winds, respectively, having periods between 1 and 10 days. For this altitude, in the winter and summer hemispheres at mid to high latitudes, the waves propagate eastward (solid lines) and westward (dashed) respectively. The waves apparently are Rossby type PWs, which slowly propagate westward (typically $-5 \mathrm{~m} / \mathrm{s}$ ) relative to the mean zonal flow (e.g. Holton, 1979; Volland, 1988). In these waves, the advective acceleration associated with the flow apparently causes the intrinsic frequency to be Doppler shifted such that the PWs appear (from the ground) to propagate in the direction of the zonal circulation, i.e. eastward in winter and westward in summer (Fig. 1b). As noted earlier (Mayr et al., 2001b), when the propagation velocities and wave periods are examined, we find that they are related to the background zonal winds. Estimating the Doppler shifted wave period to be $\tau \approx \lambda / \mathrm{U}$, where $\mathrm{U}$ is the mean zonal wind $(\mathrm{m}=0)$ and $\lambda=2 \pi r * \cos (\theta) / \mathrm{m}$ (with $\mathrm{r}$ the Earth radius and $\theta$ the latitude), one should expect that the periods are shorter at mid to high latitudes than those closer to the equator, and Fig. 10b indeed indicates that in particular for the winter hemisphere. Considering that the waves have planetary scales and the zonal winds greatly vary with latitude, it would not be meaningful to derive intrinsic periodicities or propagation velocities for these Rossby type PWs. Flow continuity requires that in Rossby waves the meridional winds increase with latitude relative to the zonal winds (Volland, 1988). 


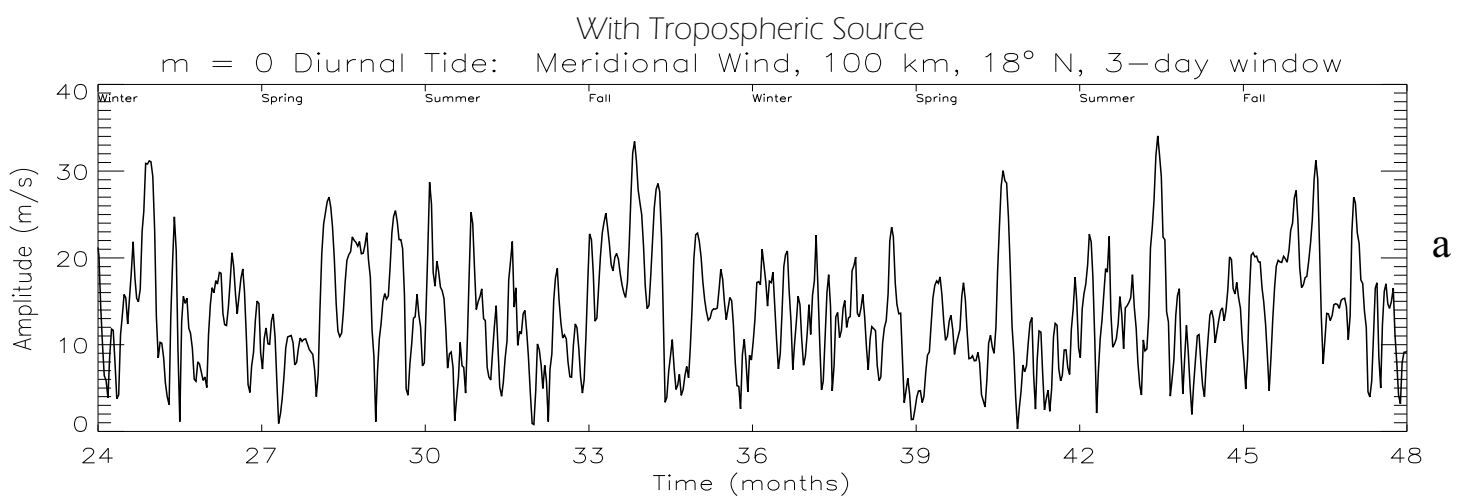

Without Tropospheric Source

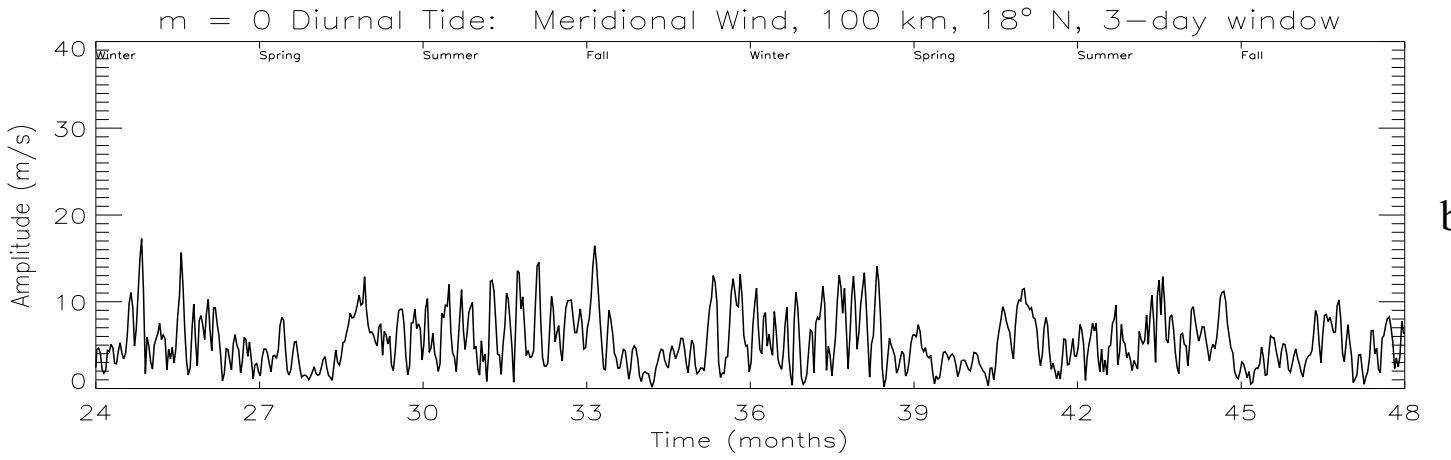

With Tropospheric Source

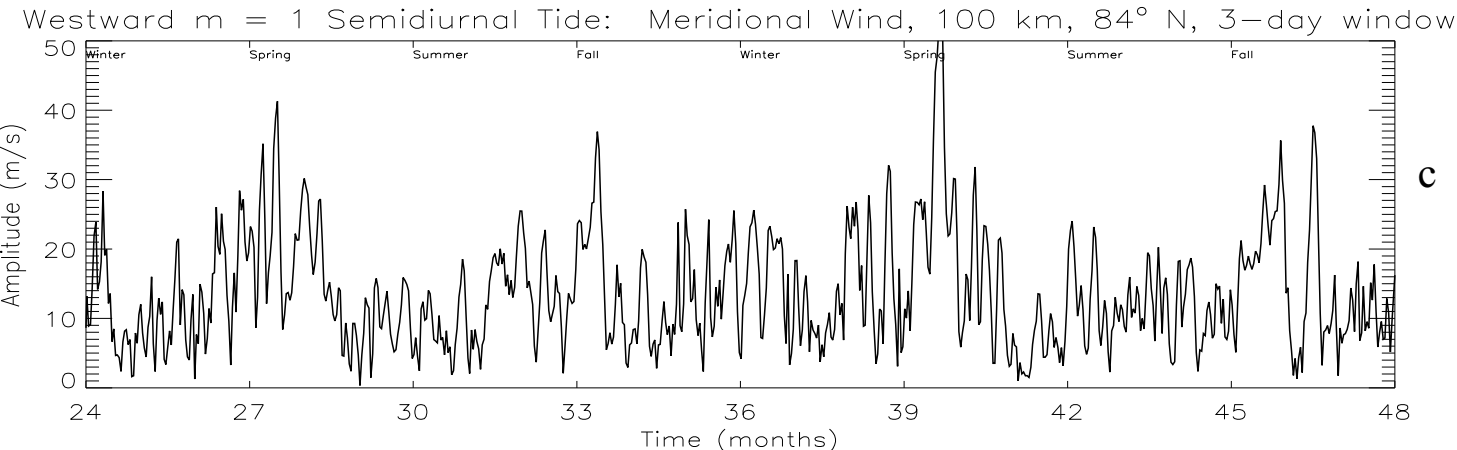

Without Tropospheric Source

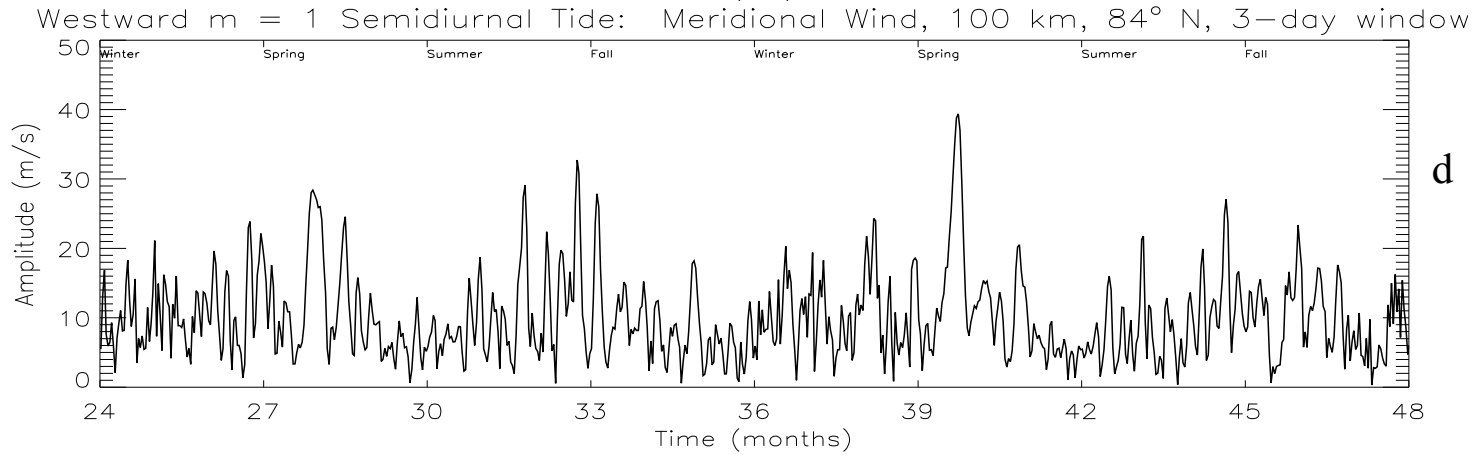

Fig. 6. Amplitudes of the $\mathrm{m}=0$ nonmigrating diurnal tide at $100 \mathrm{~km}$ altitude and $18^{\circ}$ latitude, computed with (a) and without (b) the tropospheric heat source. This tide is generated through nonlinear coupling involving the long-period $\mathrm{m}=1 \mathrm{PWs}$. The differences between (a) and (b) are large, which is consistent with the differences between the PWs shown in Figs. 4a and 5a. Analogous to (a, b) but for the m=1 nonmigrating semidiurnal tide at $84^{\circ}$ latitude (c, d), which is also generated with $\mathrm{m}=1 \mathrm{PWs}$, as Forbes et al. (1995) had proposed. 

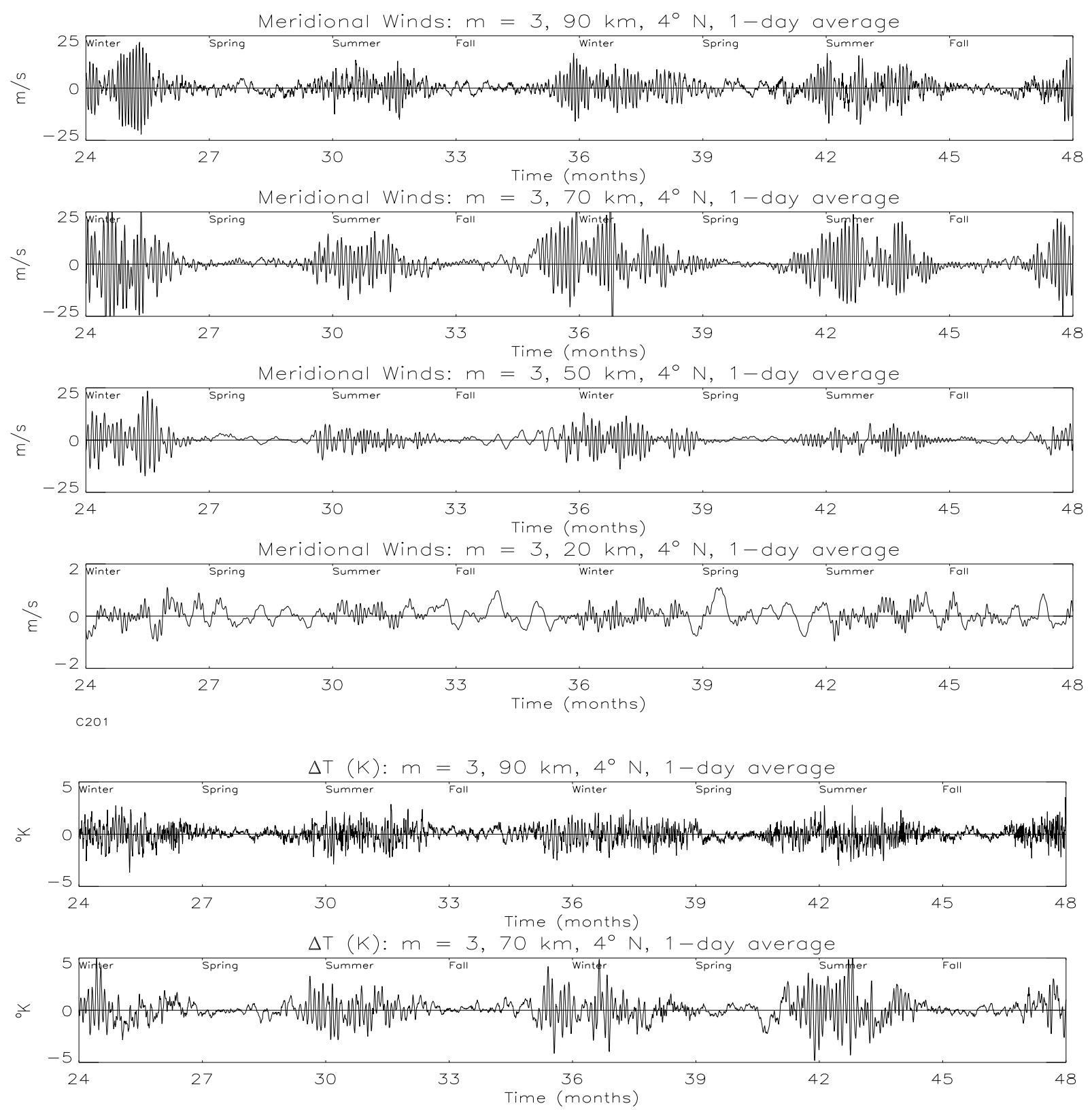

b

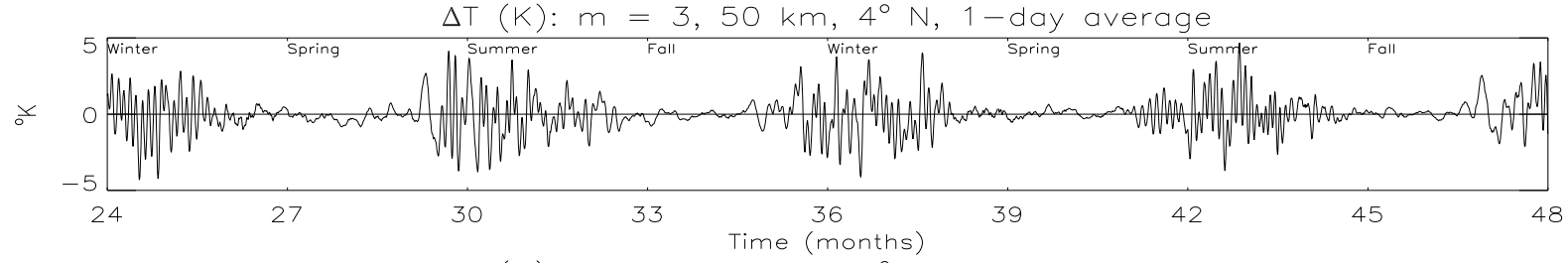

$\Delta T(K): m=3,20 \mathrm{~km}, 4^{\circ} \mathrm{N}, 1$-day average

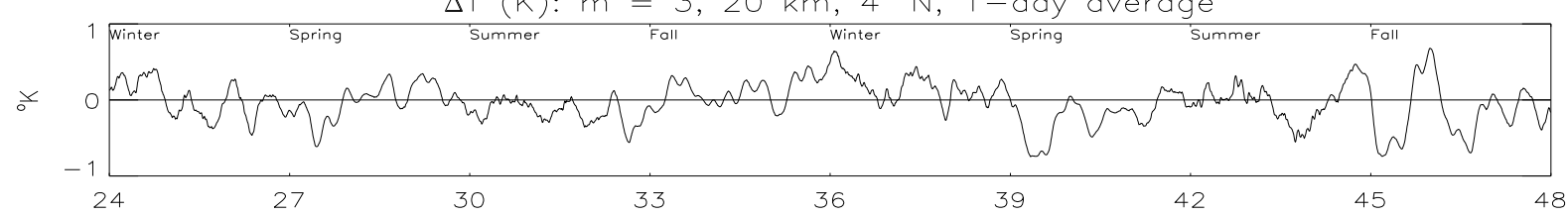

Fig. 7. Meridional winds (a) and temperature perturbations (b) of PWs for $\mathrm{m}=3$ at $4^{\circ}$ latitude and at different altitudes from 20 to $90 \mathrm{~km}$. The short period waves dominate during summer and winter months, except at $20 \mathrm{~km}$, where the long period waves are prominent. 

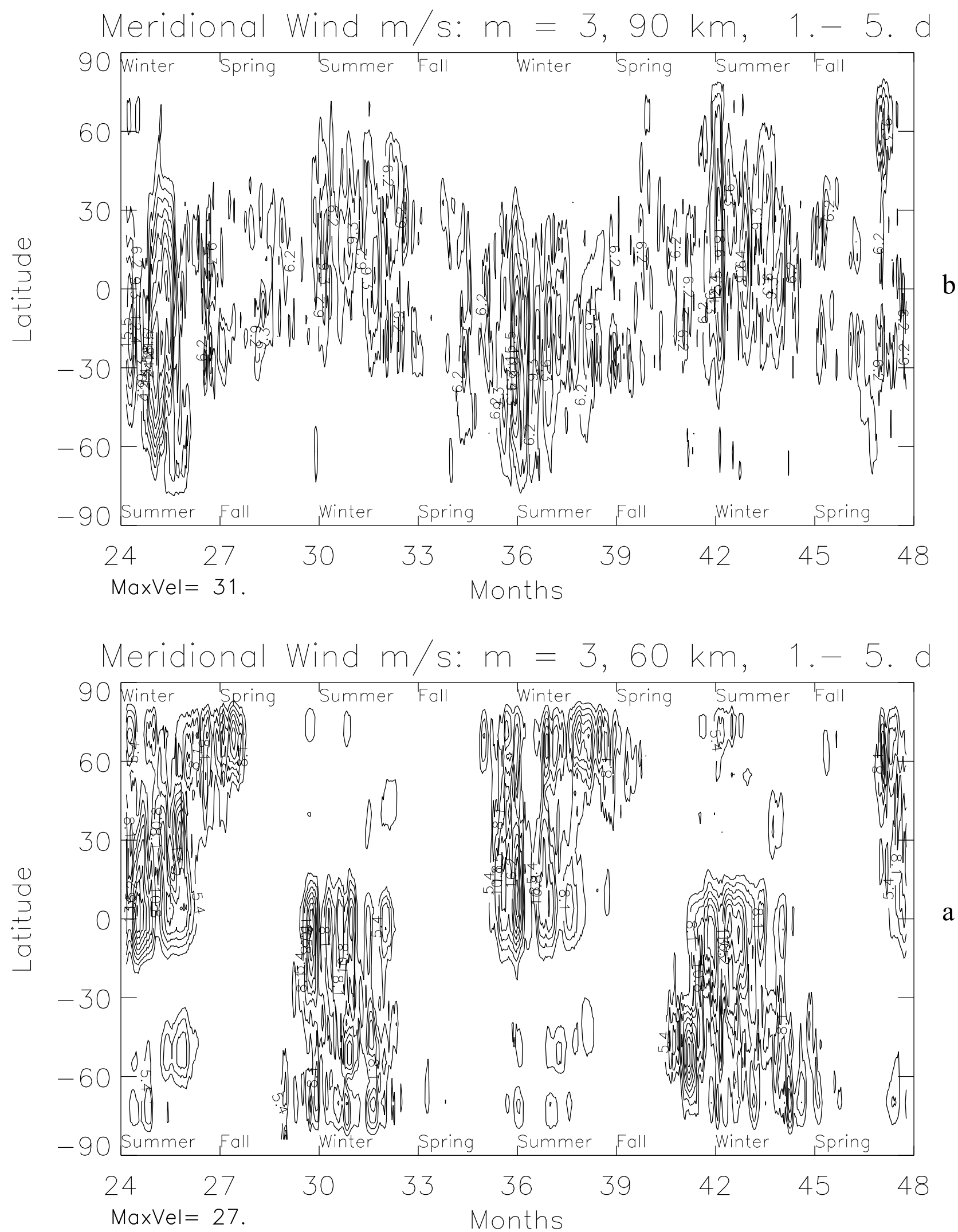

Fig. 8. Contour plot of meridional winds for PWs with $\mathrm{m}=3$ at $60 \mathrm{~km}$ (a) and $90 \mathrm{~km}$ (b) altitudes. The chosen contour intervals are about 3 $\mathrm{m} / \mathrm{s}$, and the lowest contours are suppressed to reduce clutter. Note the systematic seasonal variations, which shows that the PWs are more prevalent at $60 \mathrm{~km}$ (a) in the winter hemisphere but at $90 \mathrm{~km}$ (b) in the summer hemisphere. 

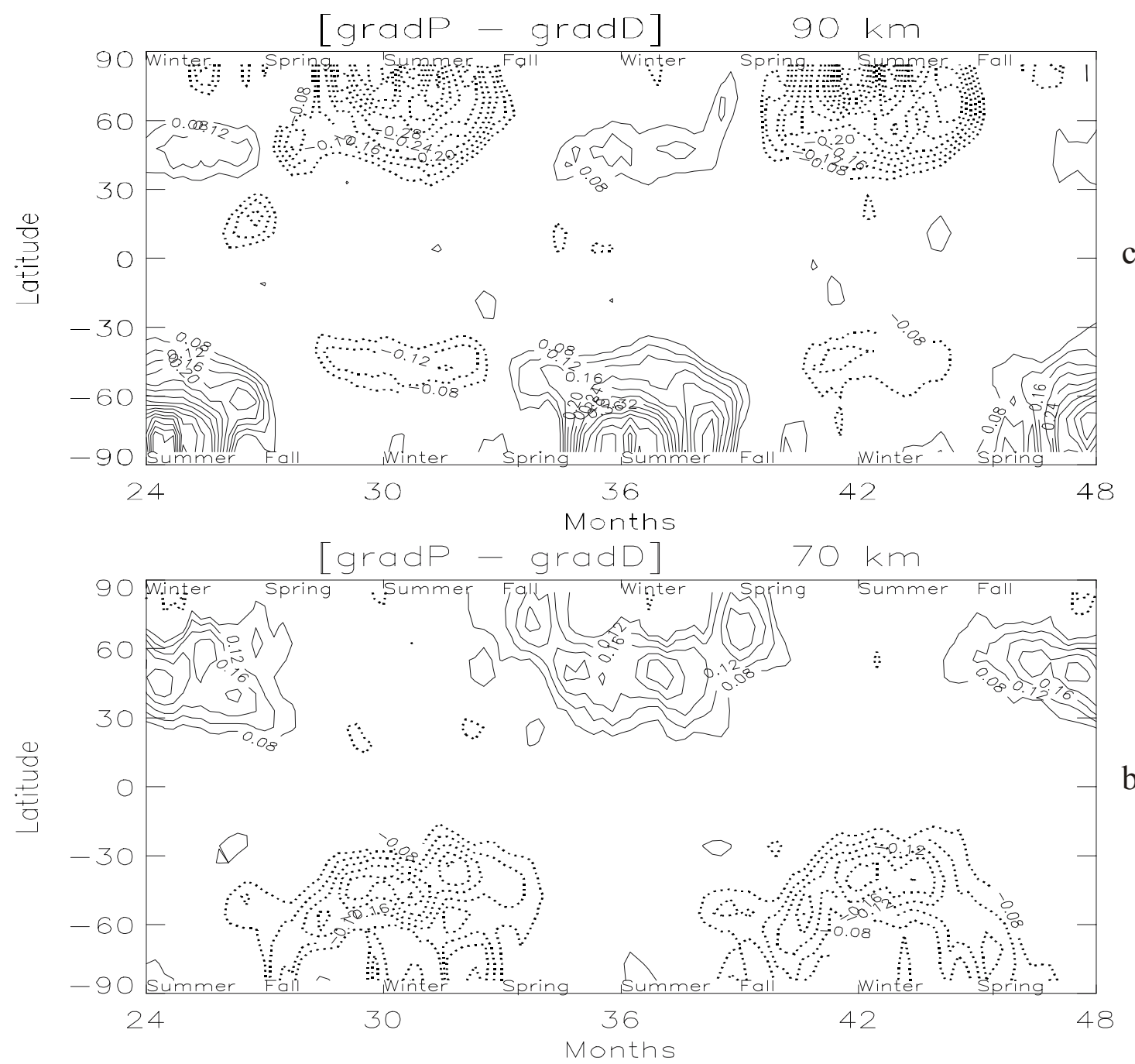

b

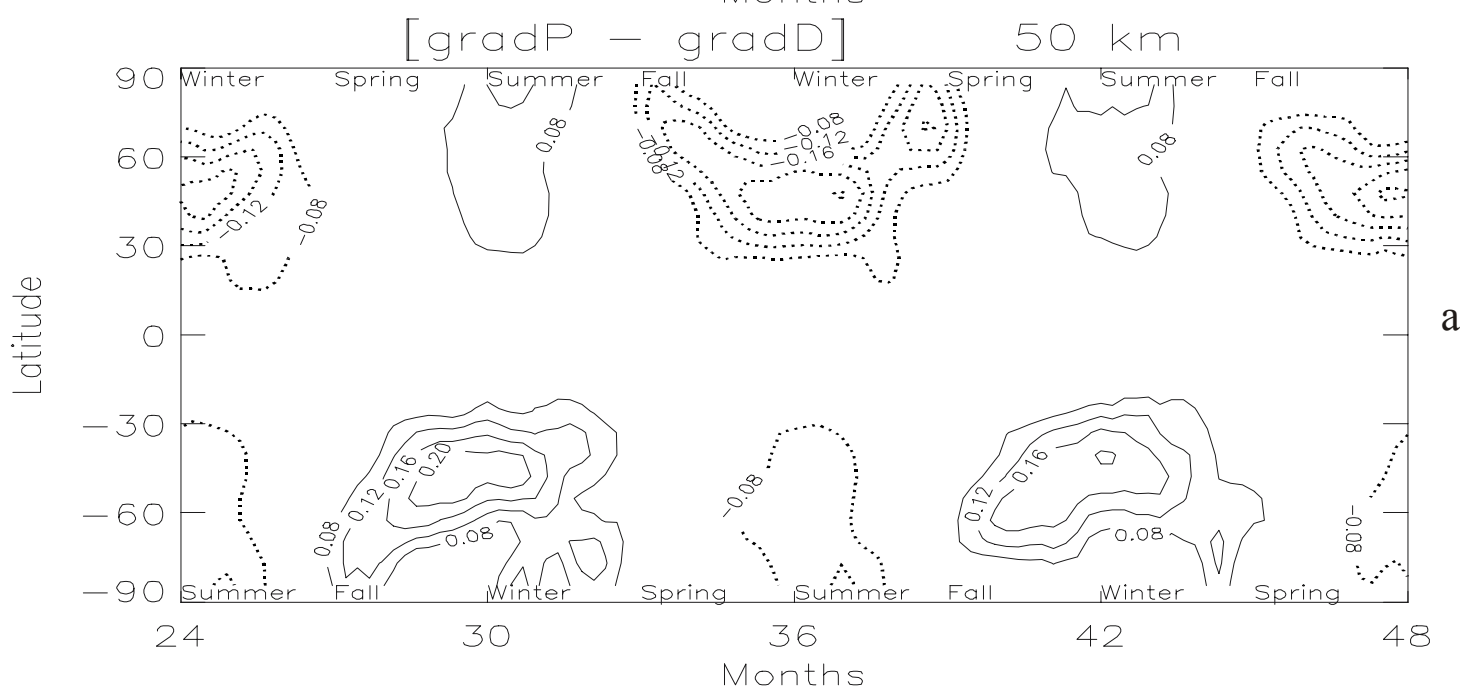

Fig. 9. Contour plots of the difference between the relative latitude gradients of pressure and density for $m=0$, which represents a measure of baroclinity. To reduce clutter, the lowest contours (0.04) are suppressed. At $50 \mathrm{~km}(\mathbf{a})$, the normalized pressure gradients are larger than the density gradients during the winter season, having opposite signs in the two hemispheres. But at $70 \mathrm{~km}$ (b), the density gradients are larger in winter, which is due to the GW driven reversal in the latitudinal temperature variation. At $90 \mathrm{~km}(\mathbf{c})$, the latter causes the largest gradients to develop in summer. 

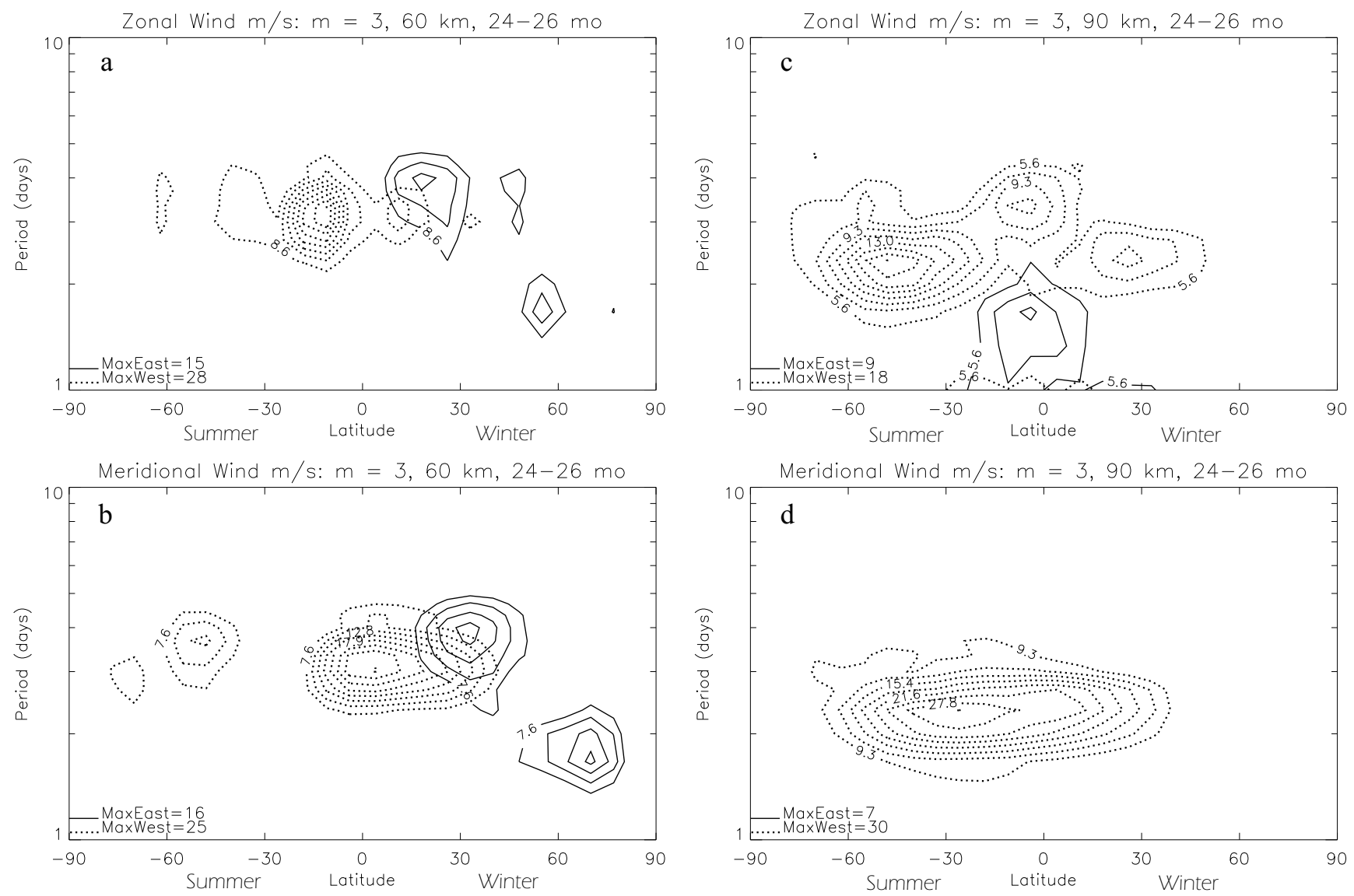

Fig. 10. Spectra of $m=3$ PWs propagating eastward (solid lines) and westward (dashed), for the zonal (a) and meridional (b) winds at $60 \mathrm{~km}$ derived from a short time span of 2 months following solstice with the Sun in the Southern Hemisphere. In the Fourier analysis, running windows are applied that are a factor 3 larger than the derive periods. To suppress chaff, the lowest $30 \%$ of the contour maxima are suppressed, but the maximum amplitudes are stated in each panel. Note the eastward propagating waves in the winter hemisphere, where the zonal jets $(\mathrm{m}=0)$ are directed eastward (Fig. 1b), and the westward propagating waves in the summer hemisphere, where the zonal jets are westward (Fig. 1b). At mid latitudes, these are presumably Rossby type PWs, which slowly propagate westward relative to the zonal winds they are embedded in. As seen from the ground, their apparent oscillation periods or propagation velocities are greatly affected (Doppler shifted) by the mean zonal winds. Westward propagating Rossby-gravity waves are apparent in the meridional wind maxima near the equator and in the zonal wind maxima that tend to straddle the equator. Analogous to (a) and (b), the zonal (c) and meridional winds (d) are presented at $90 \mathrm{~km}$. This shows that the largest PWs occur in the summer hemisphere, which is consistent with the trend seen in Fig. 8 . The eastward propagating zonal winds around the equator (Fig. 10c) represent Kelvin waves.

The amplitudes for the meridional winds (Fig. 10b) of the westward propagating Rossby-gravity waves (earlier discussed) peak near the equator, and the periods are around 3 days. Consistent with that, the zonal winds for these waves tend to straddle the equator (Fig. 10a).

The spectra for the zonal and meridional winds at $90 \mathrm{~km}$, shown, respectively, in Figs. 10c and 10d, reveal that the eastward propagating PWs no longer show up. At this altitude however, fast eastward propagating Kelvin waves appear in the zonal winds near the equator, which have periods between 1 and 2 days. The westward propagating PWs dominate, and they convey a picture in which the Rossbygravity waves near the equator seem to have merged with the westward propagating Rossby type PWs in the summer hemisphere that originate at lower altitudes.
With Fig. 11, we then present a composite picture of the altitude variations for the $\mathrm{m}=3 \mathrm{PWs}$ with periods between 1 and 5 days. Consistent with Fig. 10, the larger wave amplitudes appear near $60 \mathrm{~km}$ in the winter hemisphere but near $90 \mathrm{~km}$ in the summer hemisphere. Around the equator, the Rossby-gravity waves prevail throughout the region at least between 50 and $100 \mathrm{~km}$. At mid latitudes and around $65 \mathrm{~km}$ altitude, the Rossby type PWs dominate that are carried by the mean zonal winds such that they propagate eastward in winter and westward in summer. At $90 \mathrm{~km}$, however, the PWs propagate westward and appear preferentially in the summer hemisphere, as seen also from Fig. 8. In the zonal winds near the equator (a), there is the signature of the eastward propagating Kelvin waves at altitudes above $90 \mathrm{~km}$ that is clearly evident in Fig. 10c. 

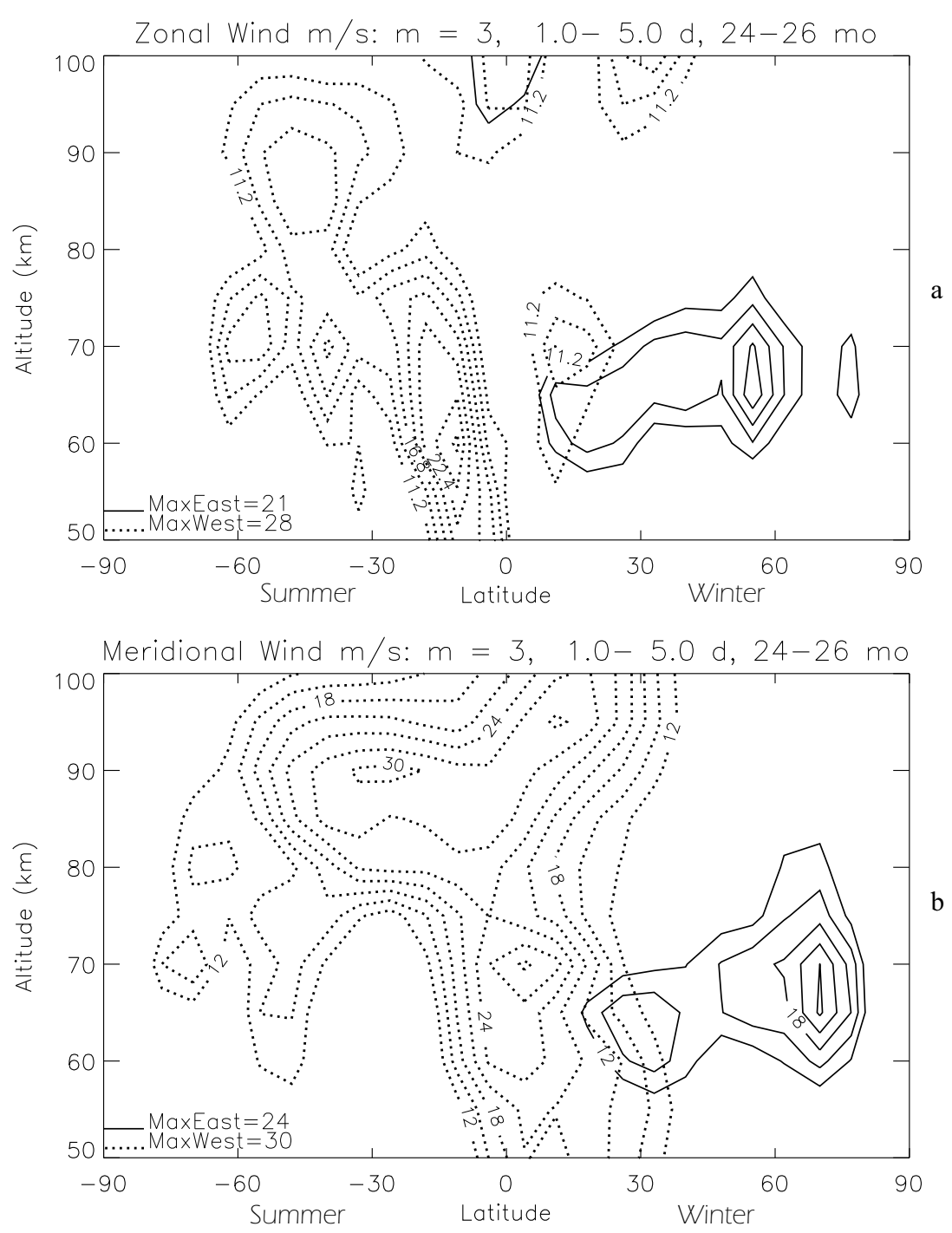

Fig. 11. Height variations of $m=3$ PWs with periods between 1 and 4 days, which bears on the results presented in Fig. 8 . It shows the Rossby type PWs at mid latitudes, eastward in winter and westward in summer, and the westward propagating Rossby-gravity waves at low latitudes. Around $65 \mathrm{~km}$, the wave activity is concentrated in the winter hemisphere, but higher up the waves are more prevalent in the summer hemisphere, as Fig. 8 shows. In the zonal winds near the equator, the Kelvin wave signature appears above $90 \mathrm{~km}$.

The PWs for $\mathrm{m}=1$ are of particular interest, because their periods are rather long, and they provide a good spectral match for interaction with the migrating tides to generate some of the largest nonmigrating tides in the mesosphere (Mayr et al., 2003). Analogous to Figs.10a and 10b, we show in Figs. 12a and $12 \mathrm{~b}$ the spectra for the $\mathrm{m}=1$ waves at $70 \mathrm{~km}$, which differ in that they do not vanish at the poles unlike those for $m>1$. (The Mercator projection is applied to expand the region at high latitudes where the waves are prominent.) The PWs at $70 \mathrm{~km}$ propagate eastward in the winter hemisphere and have periods around 4 days, while those in the summer hemisphere propagate westward with periods around 6 days. The increase in the oscillation period relative to $m=3$ and the directions of propagation in both hemispheres are qualitatively consistent with the earlier portrayed picture of Rossby type PWs that are carried (i.e. Doppler shifted) by the zonal wind field for $\mathrm{m}=0$. At $100 \mathrm{~km}$ (Figs. $12 \mathrm{c}$ and 12d), the spectra for the PWs reveal to some extent the trend seen in $\mathrm{m}=3$ (Figs. 10c and 10d). The eastward propagating PWs in winter are no longer prominent, and the westward propagating waves dominate in the summer hemisphere. Eastward propagating Kelvin waves also appear in the zonal winds at low latitudes (Fig. 12c), which have periods between 2 and 4 days.

In Fig. 13, we present the altitude variations of the zonal and meridional winds for the $\mathrm{m}=1 \mathrm{PWs}$ with periods from 3 to 10 days. This shows that the Kelvin waves in the zonal winds (Fig. 13a) near the equator are generated at altitudes above $80 \mathrm{~km}$, and such waves also arise in $\mathrm{m}=2$ (not shown) and $m=3$ (Fig. 10c). As is evident in Fig. 13, eastward and westward propagating Rossby type PWs appear, respectively, in the winter and summer hemispheres throughout the region. 

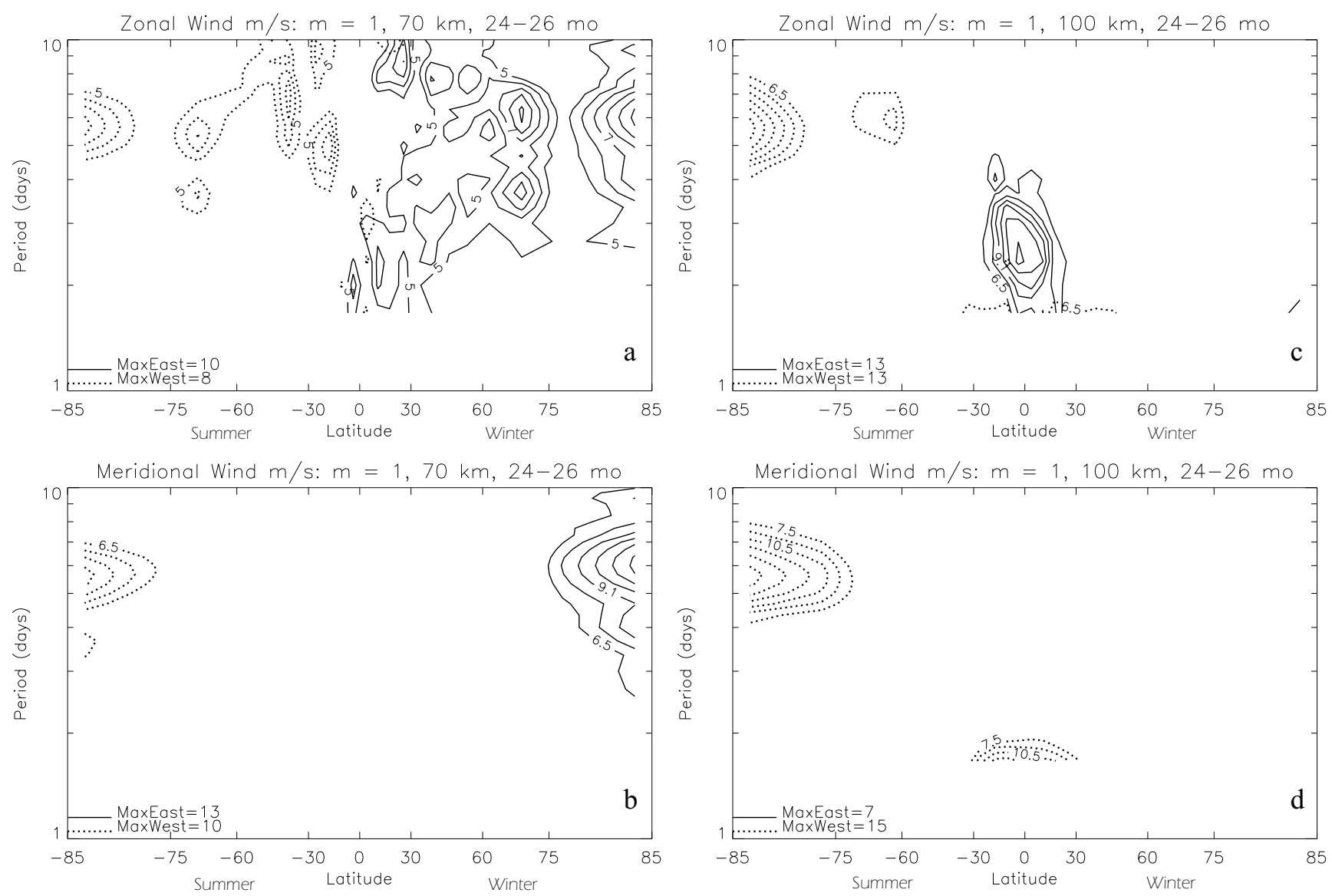

Fig. 12. Spectra for $m=1$ PWs at altitudes of $70 \mathrm{~km}(\mathbf{a}, \mathbf{b})$ and $100 \mathrm{~km}(\mathbf{c}, \mathbf{d})$. Note that for $m=1$, the waves do not vanish at the poles, unlike those for $\mathrm{m}>1$. The Mercator projection is applied to expand the regions at high latitudes where the waves are prominent. Both eastward and westward propagating Rossby type PWs are shown at $70 \mathrm{~km}$ in the winter and summer hemispheres, respectively. At $100 \mathrm{~km}$, the zonal winds near the equator (c) are again the signatures of Kelvin waves. (The westward propagating winds with periods close to 1 day near the equator are trace signatures of the diurnal tide.)

\section{Summary and conclusions}

We presented the results of a modeling study, which shows that the NSM produces PWs that have amplitudes in the mesosphere comparable to those observed. As in the model simulations of the middle atmosphere by Norton and Thuburn $(1996,1999)$, no source of any kind is prescribed to excite the waves either thermally or through momentum forcing. Of critical importance is the mean zonal circulation $(m=0)$. When we artificially suppress the solar heating that drives this circulation and the associated variations in temperature and pressure, the PWs essentially disappear. When the model is run without the excitation of the solar tides, the PWs are different but not the amplitudes in general.

In addition to the seasonal variations in the solar UV heating that drives the middle atmosphere, the model also applies a tropospheric heat source that qualitatively reproduces the observed zonal jets near the tropopause. This source proves to be significant in generating the long period planetary waves, in particular those for zonal wave numbers $m=1$ and 2 , which are involved in producing nonmigrating tides in the upper mesosphere.
The PWs in the NSM are highly variable but reveal systematic seasonal variations that could be caused by a number of processes not yet fully understood. Foremost of all is the dynamical state of the zonal mean $(\mathrm{m}=0)$, which is conducive to create instabilities. In the mesosphere, the observed reversals in the zonal circulation and latitudinal temperature variations, due to gravity wave drag (Lindzen, 1981), contributes to produce baroclinic instabilities (Plumb, 1983). A similar condition can also arise near the tropopause where zonal jets form and the latitudinal temperature variations reverse.

Three classes of PWs are generated in the model:

1. Rossby type planetary waves. These are waves that slowly propagate westward relative to the mean zonal flow. Carried by the fast zonal jets in the middle atmosphere, the waves experience Doppler shifting and thus appear (relative to the ground) to propagate eastward in winter and westward in summer.

2. Rossby-gravity waves. These waves are largely confined to low latitudes, and the most prominent manifestations are the 2 to 3 day waves for $m=3$ (and 4) in particular. They occur primarily during solstice conditions, 

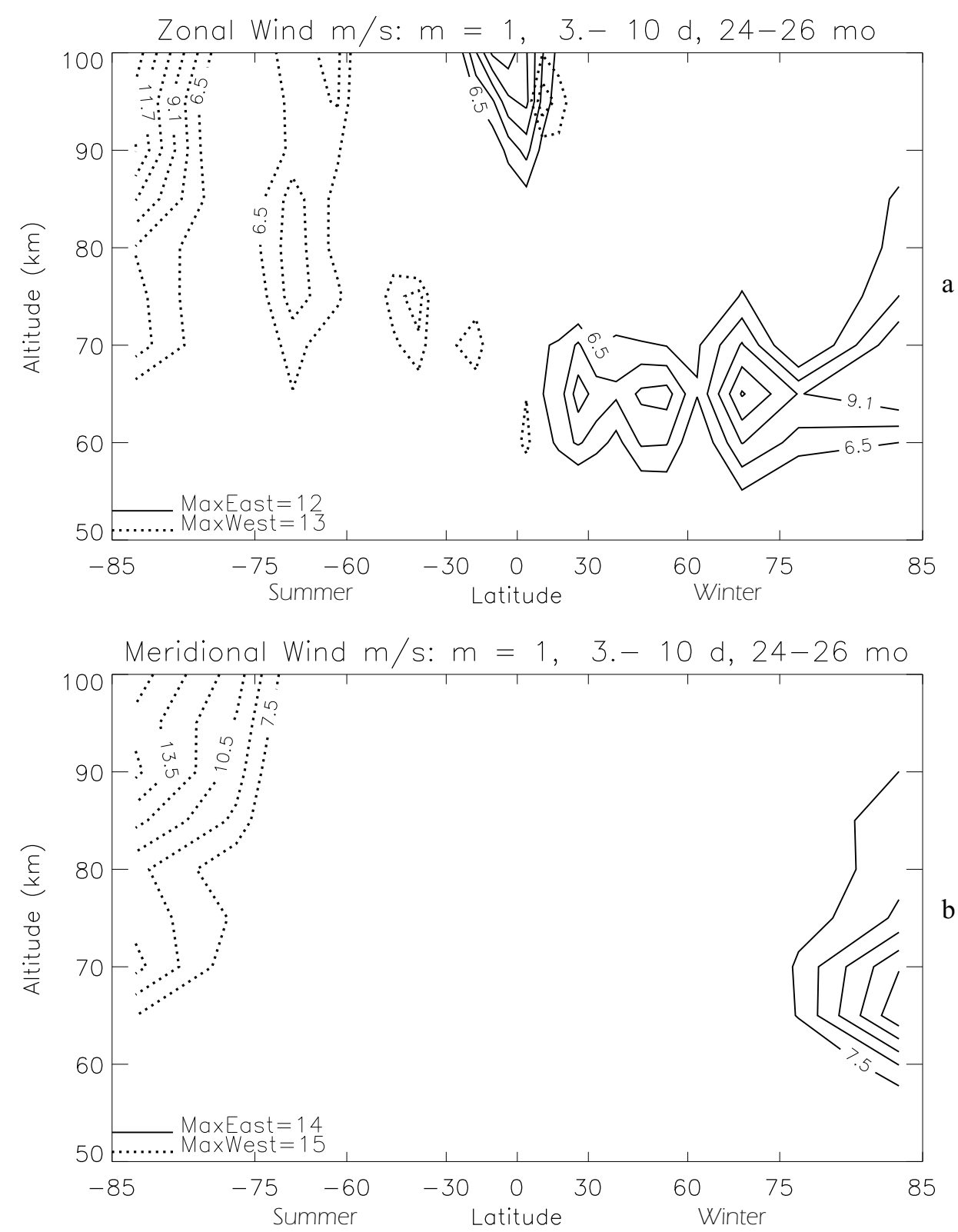

Fig. 13. Height variations of $m=1$ PWs with periods between 3 and 10 days. At mid to high latitudes, Rossby type PWs are present. Above $80 \mathrm{~km}$, Kelvin waves appear in the zonal winds. The Mercator projection is again applied.

where the temperature and pressure gradients across the equator are largest so that baroclinic instabilities develop (e.g. Plumb, 1983).

3. Kelvin waves. These waves appear at high altitudes above $80 \mathrm{~km}$ in the zonal winds near the equator for $\mathrm{m}=1$ to 3 .

The model results discussed here are representative of the season following solstice when the zonal winds in the lower mesosphere are relatively large. Closer to equinox, the PW amplitudes are generally smaller, and the apparent periods tend to be longer, often exceeding 10 days. We believe these trends can be understood. Compared to solstice condition, the latitudinal variations in pressure and temperature for $m=0$ are reduced during equinox, and this diminishes the instabilities that can generate the PWs. The related zonal winds are weaker near equinox, and the diminished (Doppler shifted) propagation velocities for Rossby type PWs imply longer oscillation periods. Our results show that the tropospheric source, and the resulting instabilities presumably, contribute significantly to the PWs that reach the upper mesosphere during equinox in particular. 
Acknowledgements. The authors are indebted to an unanimous reviewer for critical comments and valuable recommendations that contributed significantly to improve the paper. This work was performed in support of the TIMED project sponsored by NASA. Dr. Talaat's effort was supported under contract NAS5-97179 to the Johns Hopkins University, Applied Physics Laboratory. One of us (HGM) is indebted to Dr. Charles L. Wolff, Goddard, for valuable discussions. Topical Editor U.-P. Hoppe thanks R. Akmaev for his help in evaluating this paper.

\section{References}

Akmaev, R. A.: Simulation of large-scale dynamics in the mesosphere and lower thermosphere with the Doppler-spread parameterization of gravity waves: 1 . Implementation and zonal mean climatologies, J. Geophys. Res., 106, 1193, 2001.

Burks, D. and Leovy, C.: Planetary waves near the mesospheric easterly jet, Geophys. Res. Lett., 13, No. 3, 193, 1986.

Chan, K. L., Mayr, H. G., Mengel, J. G., and Harris, I., A "stratified" spectral model for stable and convective atmospheres, J. Comp. Phys., 113, 165, 1994.

Clark, R. R., Current, A. C., and Manson, A. H., et al.: Global properties of the 2-day wave from mesosphere lower-thermosphere radar observations, J. Atmos. Terr. Phys., 56, 1279, 1994.

Craig, R. L. and Elford, W. G.: Observations of the quasi 2-day wave near $90 \mathrm{~km}$ altitude at Adelaide $\left(33^{\circ} \mathrm{S}\right)$, J. Atmos. Terr. Phys., 43, 1051, 1981.

Deng, W., Salah, J. E., Clark, R. R., et al.: Coordinated global radar observations of tidal and planetary waves in the mesosphere and lower thermosphere during 20 to 30 January, 1993, J. Geophys. Res., 102, 7307, 1997.

Dunkerton, T. J., A two-dimensional model of the quasi-biennial oscillation, J. Atmos. Sci., 42,1151 (1985).

Dunkerton, T. J.: The role of gravity waves in the quasi-biennial oscillation, J. Geophys. Res., 102, 26 053, 1997.

Forbes, J. M. and Garrett, H. B.: Thermal excitation of atmospheric tides due to insolation absorption by $\mathrm{O}_{3}$ and $\mathrm{H}_{2} \mathrm{O}$, Geophys. Res. Lett., 5, 1013, 1978.

Forbes, J. M.: Tidal and planetary waves, Geophysical Monograph 87, 67, 1995.

Forbes, J. M., Makarov, N. A., and Portnyagin, Y. I.: First results from the meteor radar at South Pole: A large 12-hour oscillation with zonal wave-number one, Geophys. Res. Lett., 22, 3247, 1995.

Fraser, G. J., Hernadez, G., and Smith, R. W.: Eastward moving 24-day waves in the winter antarctic mesosphere, Geophys. Res. Lett., 20, 1547, 1993.

Fritts, D. C. and Isler, J. R.: Mean motion and tidal and 2-day structure and variability in the mesosphere and lower thermosphere, J. Atmos. Sci., 51, 2145, 1994.

Fritts, D. C., Isler, J. R., and Lieberman, R. S. et al.: Two-day wave structure and mean flow interactions observed by radar and High Resolution Doppler Imager, J. Geophys. Res., 104, 3953, 1999.

Gray, L. J. and Pyle, J. A.: A two dimensional model of the quasibiennial oscillation of ozone, J. Atmos. Sci., 46, 203, 1989.

Harris, T. J. and Vincent, R. A.: The quasi-two-day wave observed in the equatorial middle atmosphere, J. Geophys. Res., 98, $10481,1993$.

Harris, T. J.: A long-term study of the quasi 2-day wave in the middle atmosphere, J. Atm. Terr. Phys., 56, 569, 1994.
Hays, P. B., Abreu, J., and Dobbs, M. E. et al.: The high-resolution doppler imager on the upper atmosphere research satellite, J. Geophys. Res., 98, 10713, 1993.

Held, I. M. and Hou, A. Y.: Nonlinear axially symmetric circulation in a near inviscid atmosphere, J. Atmos. Sci., 37, 515, 1980.

Hines, C. O.: The saturation of gravity waves in the middle atmosphere. Part I: Critique of linear instability theory, J. Atmos. Sci., 48, 1348, 1991a.

Hines, C. O.: The saturation of gravity waves in the middle atmosphere. Part II: Development of Doppler spread theory, J. Atmos. Sci., 48, 1360, $1991 b$.

Hines, C. O.: Doppler-spread parameterization of gravity-wave momentum deposition in the middle atmosphere, 1 , Basic formulation, J. Atmos. Solar Terr. Phys., 59, 371, 1997a.

Hines, C. O.: Doppler-spread parameterization of gravity-wave momentum deposition in the middle atmosphere, 2, Broad and quasi monochromatic spectra, and implementation, J. Atmos. Solar Terr. Phys., 59, 387, 1997b.

Hines, C. O.: Theory of the Eulerian tail in the spectra of atmospheric and oceanic internal gravity waves, J. Fluid Mech., 448, 289, 2001.

Hines, C. O.: Nonlinearities and linearities in internal gravity waves of the atmosphere and the oceans, Geophys. Astrophys. Fluid, 96, 1, 2002.

Holton, J. R.: An introduction to dynamic meteorology, Academic Press, 1979.

Holton, J. R.: The generation of mesospheric planetary waves by zonally asymmetric gravity wave breaking, J. Atmos. Sci., 41, 3427, 1984.

Kinnersley, J. S. and Pawson, S.: The descent rates of the shear zones of the equatorial QBO, J Atmos. Sci., 53, 1937 (1996).

Lindzen R. S. and Holton, J. R.: A theory of the quasi-biennial oscillation, J. Atmos. Sci., 25, 1095, 1968.

Lindzen R. S.: Turbulence and stress due to gravity wave and tidal breakdown, J. Geophys. Res., 86, 9707, 1981.

Lindzen, R. S., and Hou, A. Y., Hadley circulations for zonally averaged heating centered off the equator, J. Atmos. Sci., 45, 4073, 1988.

Manzini, E., McFarlane, N. A., and McLandress, C.: Impact of the doppler spread parameterization the simulation of the middle atmosphere circulation using the MA/ECHAM4 general circulation model, J. Geophys. Res., 102, 25 751, 1997.

Mayr, H. G, Mengel, J. G., Hines, C. O., Chan, K. L., Arnold, N. F., Reddy, C. A., and Porter, H. S.: The gravity wave doppler spread theory applied in a numerical spectral model of the middle atmosphere, 2, Equatorial oscillations, J. Geophys. Res., 102, 26093 (1997).

Mayr, H. G, Mengel, J. G., Chan, K. L., and Porter, H. S.: Mesosphere dynamics with gravity forcing: Part I, Diurnal and semidiurnal tides, J. Atm. Solar-Terr. Phys., 63, 1851, 2001 a.

Mayr, H. G, Mengel, J. G., Chan, K., L., and Porter, H. S.: Mesosphere dynamics with gravity forcing: Part II, Planetary waves, J. Atm. Solar-Terr. Phys., 63, 1865, 2001b.

Mayr, H. G., Mengel, J. G., Talaat, E. R., Porter, H. S., and Chan, K. L.: Non-migrating diurnal tides generated with planetary waves in the mesosphere, Geophys. Res. Lett., 30 (16), 1832, 2003.

Meek, C. E., Manson, A. H., and Franke, S. J. et al.: Global study of northern hemisphere quasi 2-day wave events in recent summers near 90 km altitude, J. Atm. Terr. Phys., 58, 1401, 1996.

Mengel, J. G., Mayr, H. G., Chan, K. L., Hines, C. O., Reddy, C. A., Arnold, N. F., and Porter, H. S.: Equatorial oscillations in the middle atmosphere generated by small scale gravity waves, 
Geophys. Res. Lett., 22, 3027, 1995.

Mote, P. W., Rosenlof, K. H., and McIntyre, M. E. et al.:An atmospheric tape recorder: The imprint of tropical tropopause temperatures on stratospheric water vapor, J. Geophys. Res., 101, 3989, 1996.

Muller, H. G. and Nelson, L.: A traveling quasi 2-day wave in the meteor region, J. Atm. Terr. Phys., 40, 761, 1978.

Norton, W. A. and Thuburn, J.: The two-day wave in a middle atmosphere GCM, Geophys. Res. Lett., 23, 2113, 1996.

Norton, W. A. and Thuburn, J.: Sensitivity of mesospheric mean flow, planetary waves and tides to strength of gravity wave drag, J. Geophys. Res., 104, 30 897, 1999.

Pfister, L.: Baroclinic instability or easterly jets with application to the summer mesosphere, , J. Atmos. Sci., 42, 313, 1985.

Phillips, A.: Simultaneous observations of the quasi 2-day wave at Manson, Antarctica, and Adelaide, South Australia, J. Atm. Terr. Phys., 51, 761, 1989.

Plumb, R. A.: Baroclinic instability of the summer mesosphere: A mechanism for the quasi-2-day wave?, J. Atmos. Sci., 40, 262, 1983.

Plumb, R. A., Vincent, R. A., and Craig, R. L.: The quasi-2-day wave event of January 1984 and its impact on the mean mesospheric circulation, J. Atmos. Sci., 44, 3030, 1987.

Plumb, R. A. and Hou, A. Y.: The response of a zonally symmetric atmosphere to subtropical thermal forcing: Threshold behavior, J. Atmos. Sci., 49, 1790, 1992.

Poole, L. M. G.: The characteristics of mesospheric two-day wave as observed at Grahamstown $\left(33.3^{\circ} \mathrm{S}, 26.5^{\circ} \mathrm{E}\right)$, J. Atm. Terr. Phys., 52, 259, 1990.

Shepherd, G. G., Thuillier, G., Gault, W. A. et al.: WINDII, the wind imager interferometer on the upper atmosphere research satellite, J. Geophys. Res., 98, 107 725, 1993.

Smith, A. K.: Longitudinal variations in mesospheric winds: Evidence for gravity wave filtering by planetary waves, J. Atmos. Sci., 53, 1156, 1996.

Smith, A. K.: Stationary planetary waves in upper mesospheric winds, J. Atmos. Sci., 54, 2129, 1997.
Strobel, D. F.: Parameterization of atmospheric heating from 15 to $120 \mathrm{~km}$ due to O2 and O3 absorption of solar radiation, J. Geophys. Res., 83, 6225, 1978.

Talaat, E. R. and Lieberman, R. S.: Nonmigrating diurnal tides in mesospheric and lower thermospheric winds and temperatures, J. Atmos. Sci., 56, 4073-4087, 1999.

Talaat, E. R., Yee, J.-H., and Zhu, X.: Observations of the 6.5 day wave in the mesosphere and lower thermosphere. J. Geophys. Res., 106, 20715-20 723, 2001.

Teitelbaum, H. and Vial F.: On tidal variability induced by nonlinear interaction with planetary waves, J. Geophys. Res., 96, 14 169$14178,1991$.

Tsuda, T., Kato, S., and Vincent, R. A.: Long period oscillations observed by the Kyoto meteor radar and comparison of the quasi 2-day wave with Adelaide MF radar observations, J. Atm. Terr. Phys., 50, 225, 1988.

Volland, H.: Atmospheric Tidal and Planetary Waves, Kluwer Academic Publ., Boston, MA, 1988.

Wang, D. W., Ward, W. E., Shepherd, G. G., and Wu, D. L.: Stationary planetary waves inferred from WINDII wind data taken within altitudes 90-120 km during 1991-96, J. Atmos. Sci., 57, 1906, 2000.

Wehrbein, W. M. and Leovy, C. B.: An accurate radiative heating and cooling algorithm for use in a dynamical model of the middle atmosphere, J. Atmos. Sci., 39, 1532, 1982.

Williams, P. J., Mitchell, N. J., Beard, A. G., Howells, V. S., and Muller, H. G.: The coupling of planetary waves, tides, and gravity waves in the mesosphere and lower thermosphere, Adv. Space Res., 24, 1571, 1999.

Wu, D. L., Hays, P. B., and Skinner, W. R., et al.: Observations of the quasi 2-day wave from the high resolution doppler imager on UARS, Geophys. Res. Lett., 20, 2853, 1993.

Wu, D. L., Hays, P. B., and Skinner, W. R.: Observations of the 5day wave in the mesosphere and lower thermosphere, Geophys. Res. Let., 21, 2733-2736, 1994.

Zhu, X.: Radiative cooling calculated by random band models with S-1-beta tailed distribution, J. Atmos. Sci., 46, 511, 1989. 